\title{
Comparison of Static Pressure from Aircraft Trailing Cone Measurements and Numerical Weather Prediction Analysis
}

Andreas Giez, Christian Mallaun, Martin Zöger,

\section{Andreas Dörnbrack and Ulrich Schumann}

German Aerospace Center,

Flight Experiments and Institute of Atmospheric Physics,

Oberpfaffenhofen, Germany

- Height-keeping performance of aircraft is a key element in ensuring safe operations in RVSM airspace.

- Accurate pressure -geopotential relation is fundamental for meteorology

- We compare Trailing Cone (TC) and Numerical Weather Prediction (NWP) data

- The accuracy of the TC and NWP data is useful for control of height keeping performance and assessment of weather analysis 


\section{Pressure sensors on HALO}

the German High Altitude and Long Range Research Aircraft, a Gulfstream G550

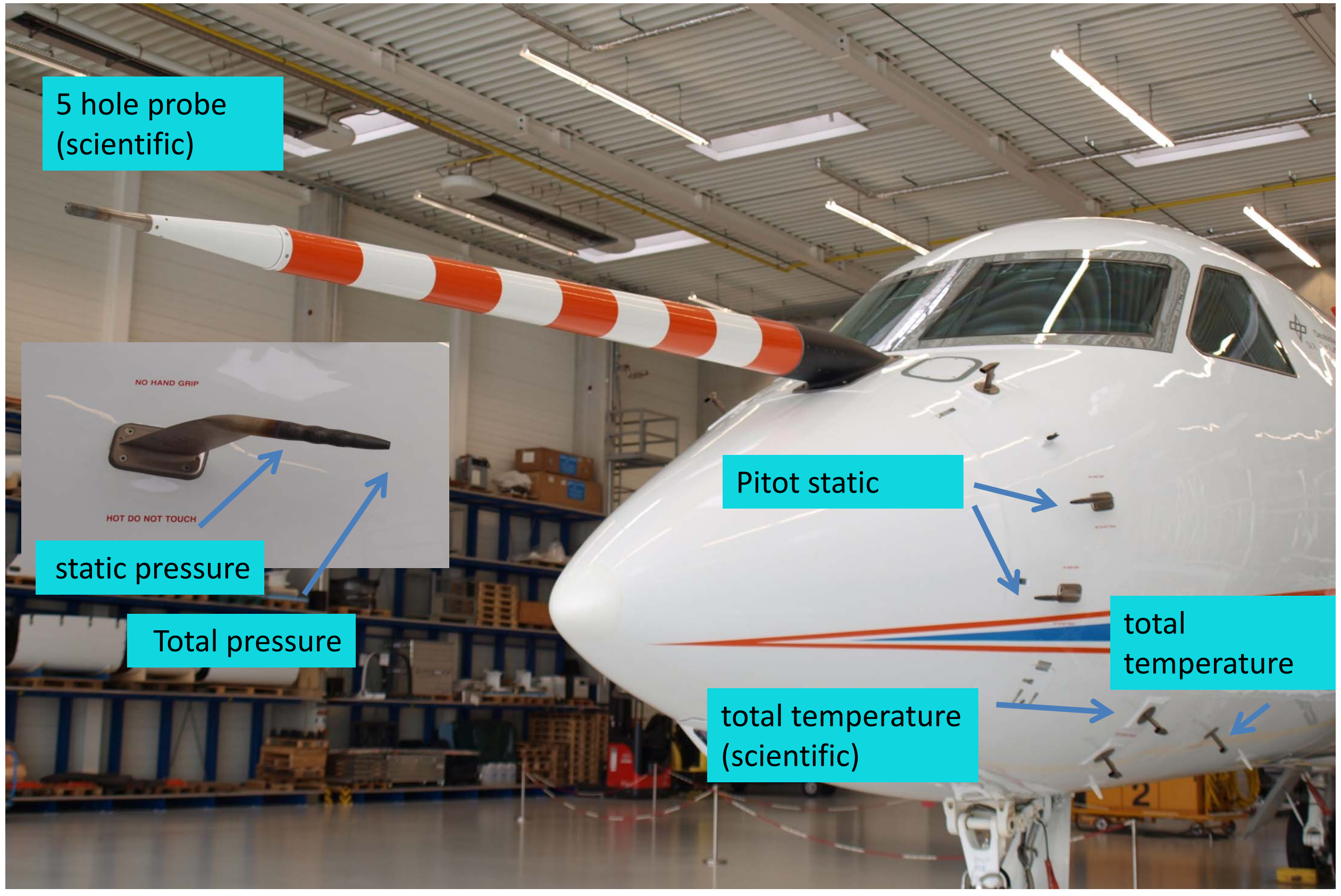




\section{Pressure sensors on FALCON}

a Dassault Mystère Falcon 20-E5
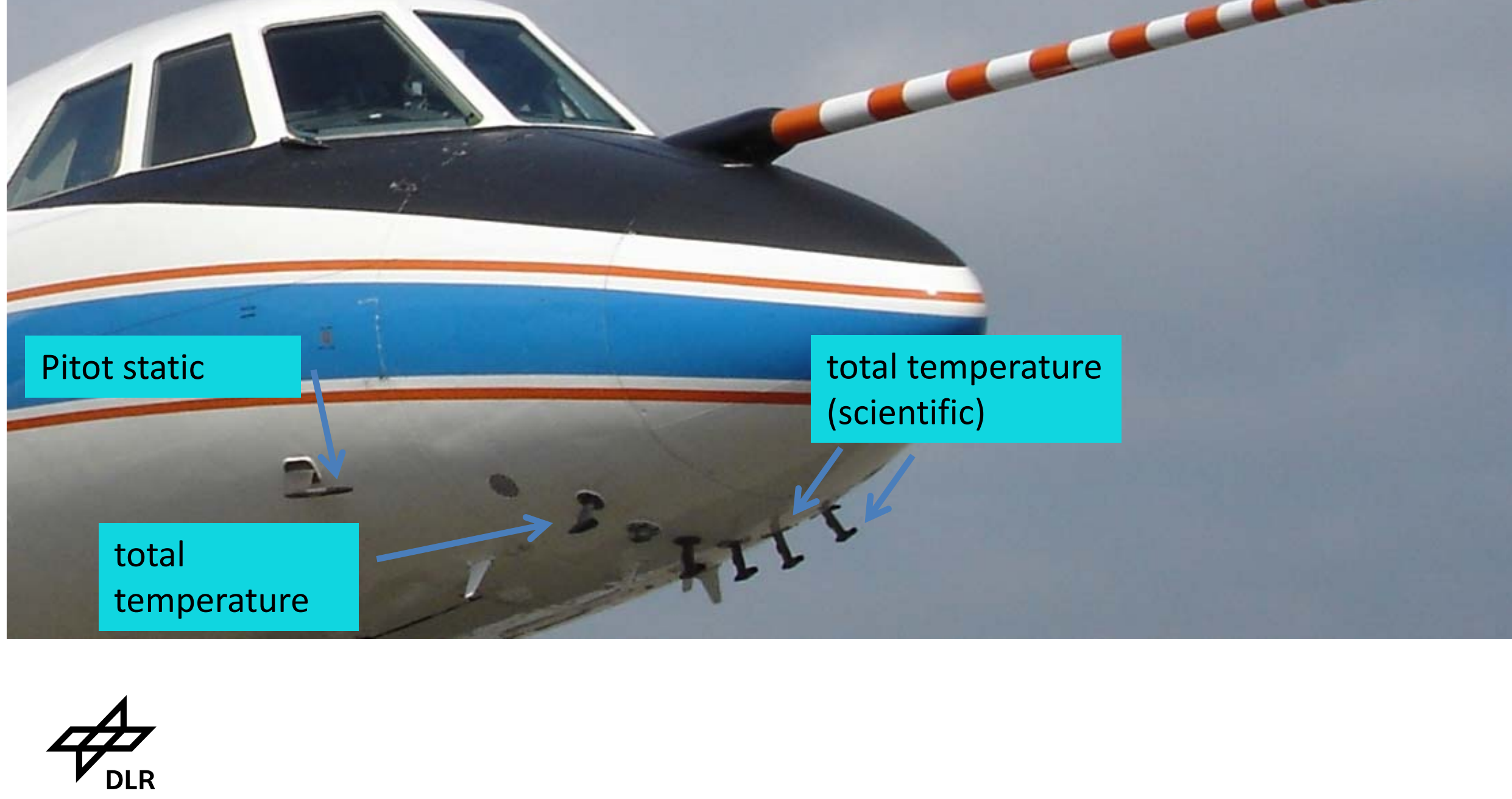


\section{A well-known problem: Aerodynamic disturbance of static pressure distribution along an aircraft}

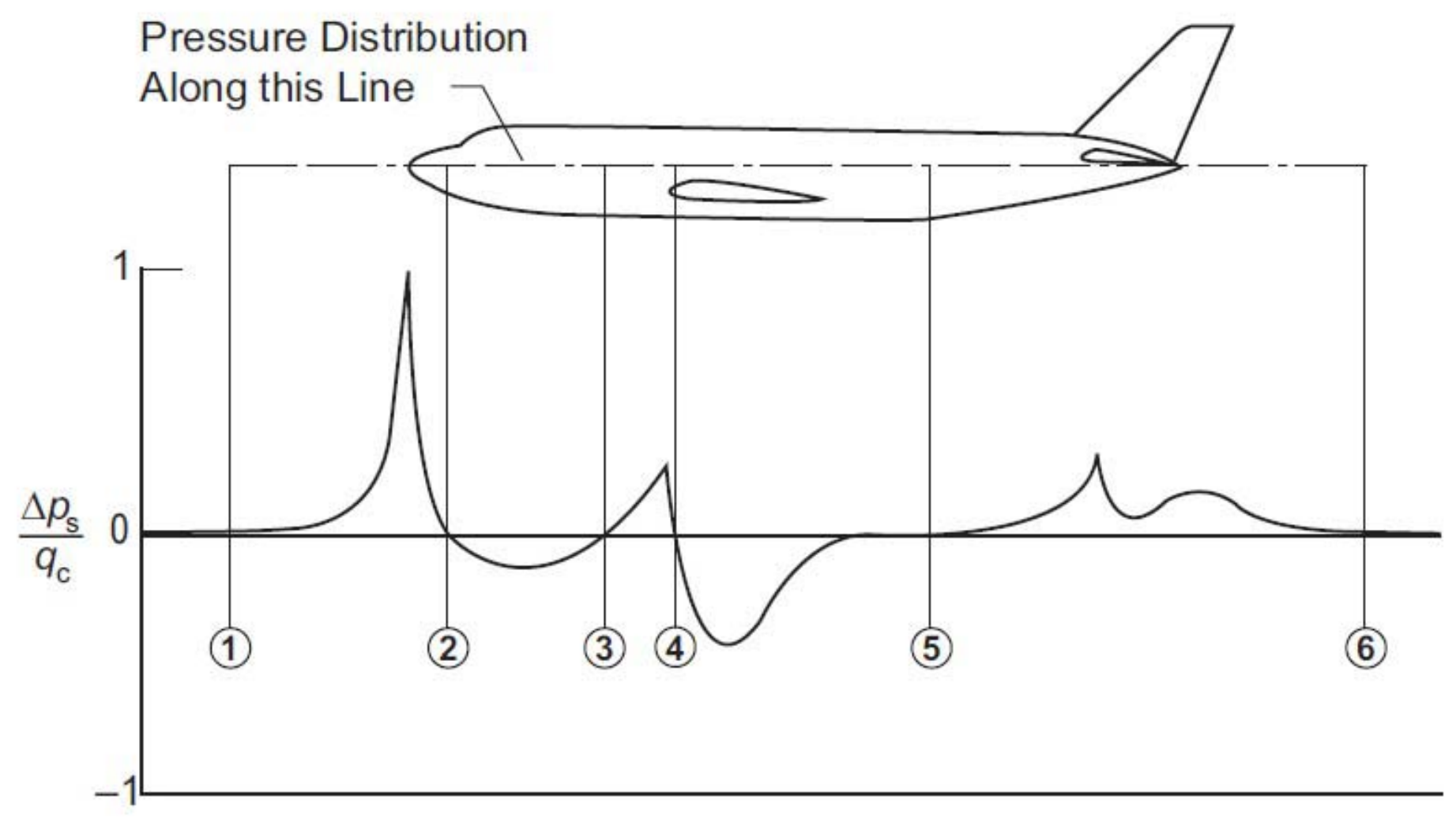

DeLeo and Hagen (1966) 


\section{Importance of static pressure $p$}

- aviation

height in standard atmosphere

$$
z=H_{\text {ICAO }}(p)
$$

static temperature from total

$$
\frac{T_{t o t}}{T}=\left(\frac{p_{t o t}}{p}\right)^{\frac{\gamma-1}{\gamma}}
$$

Mach number

$$
\begin{aligned}
& M=\left(\frac{2}{\gamma-1}\right)^{1 / 2}\left[\left(\frac{p_{\text {tot }}}{p}\right)^{\frac{\gamma-1}{\gamma}}-1\right]^{1 / 2} \\
& \gamma=\frac{c_{p}}{c_{v}}=1.4
\end{aligned}
$$$$
\text { Anderson (2010) }
$$

- meteorology

$$
\begin{aligned}
& \begin{array}{l}
\text { hydrostatic pressure } \\
d p=-\rho g d z=-
\end{array} \frac{p}{R_{d r y} T_{V}} d \Phi \\
& \text { equation of state } \\
& \rho=\frac{p}{R_{d r y} T_{v}} \quad T_{v}=T(1+\varepsilon q) \\
& \varepsilon=R_{d r y} / R_{v a p}-1
\end{aligned}
$$

geopotential

$$
\Phi(z)=\int_{0}^{z} g\left(z^{\prime}\right) d z^{\prime}
$$

$$
\vec{V}=\frac{\vec{k}}{f} \times \nabla_{p} \Phi
$$

Holton (2012) 


\section{Method for determination of pressure/height deviations, $\Delta z$ and $\Delta p$}

\begin{tabular}{|c|c|}
\hline $\begin{array}{l}\text { A) Measurement at aircraft }(A C) \text { : } \\
\text { GNSS -> Height above NN: } z_{A C} \\
\text { AC sensor }->\text { Static pressure: } p_{A C}\end{array}$ & $\begin{array}{l}\text { C) Height and } \\
\text { pressure deviation }\end{array}$ \\
\hline $\begin{array}{l}\text { B) Numerical weather prediction (NWP) } \\
\text { from analysis or prediction }\end{array}$ & \\
\hline $\begin{array}{l}\text { 1) Altitude for given pressure } p_{A C}=p_{N W P} \\
->z_{N W P}\end{array}$ & $\Delta \mathrm{z}=\mathrm{z}_{\mathrm{AC}}-\mathrm{z}_{\mathrm{NWP}}$ \\
\hline $\begin{array}{l}\text { 2) Pressure for given height } z_{A C}=z_{N W P} \\
->p_{N W P}\end{array}$ & $\Delta p=p_{A C}-p_{N W P}$ \\
\hline
\end{tabular}




\section{Is NWP accurate enough?}

Can it be used for checking pressure altitude measurements?

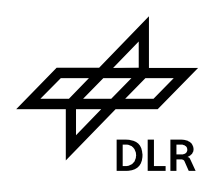

\section{The quiet revolution of numerical weather prediction}

Peter Bauer $^{1}$, Alan Thorpe $^{1}$ \& Gilbert Brunet ${ }^{2}$

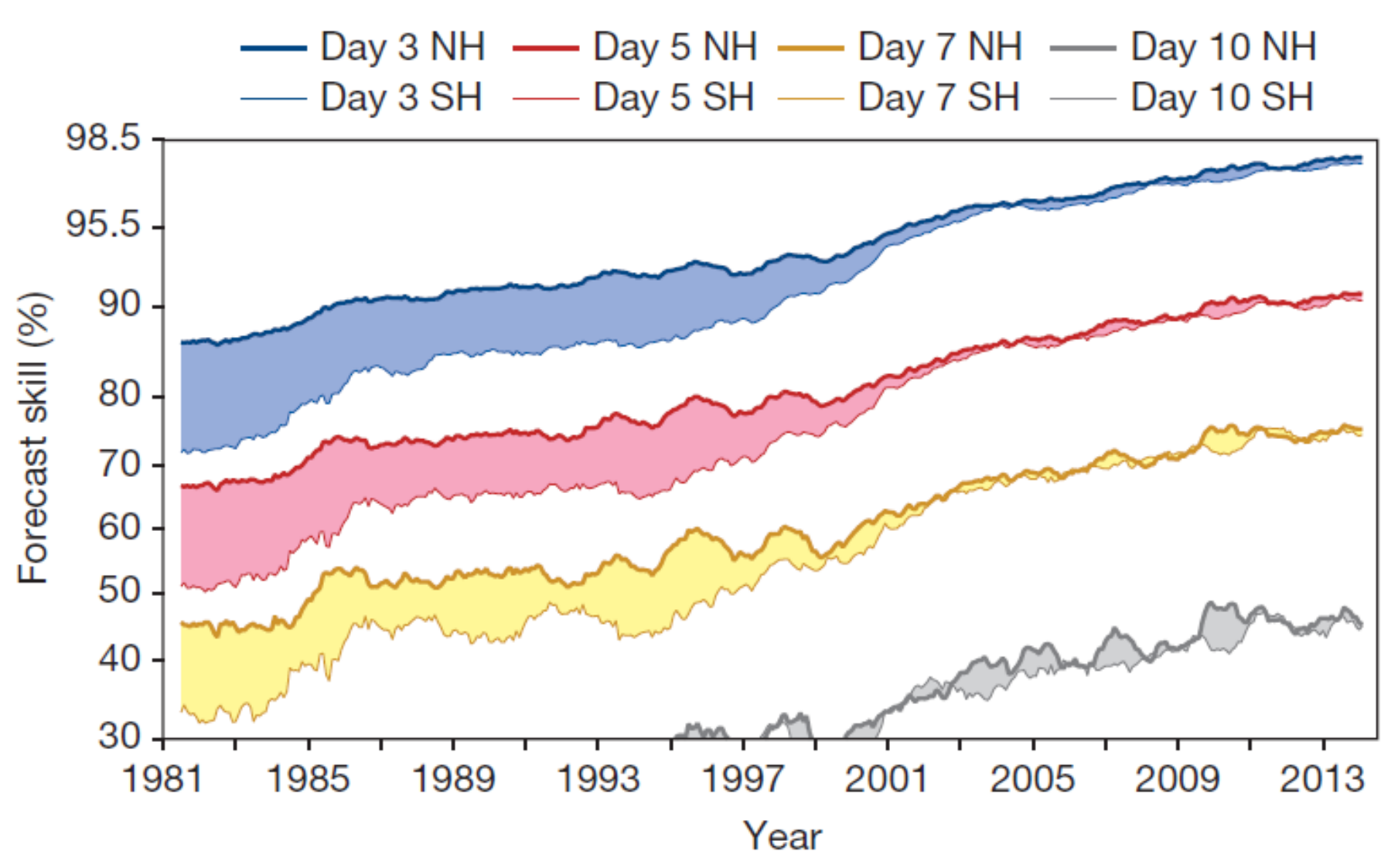




\section{2-day forecast, $500 \mathrm{hPa}$ geopotential: rms order $15 \mathrm{~m}$}
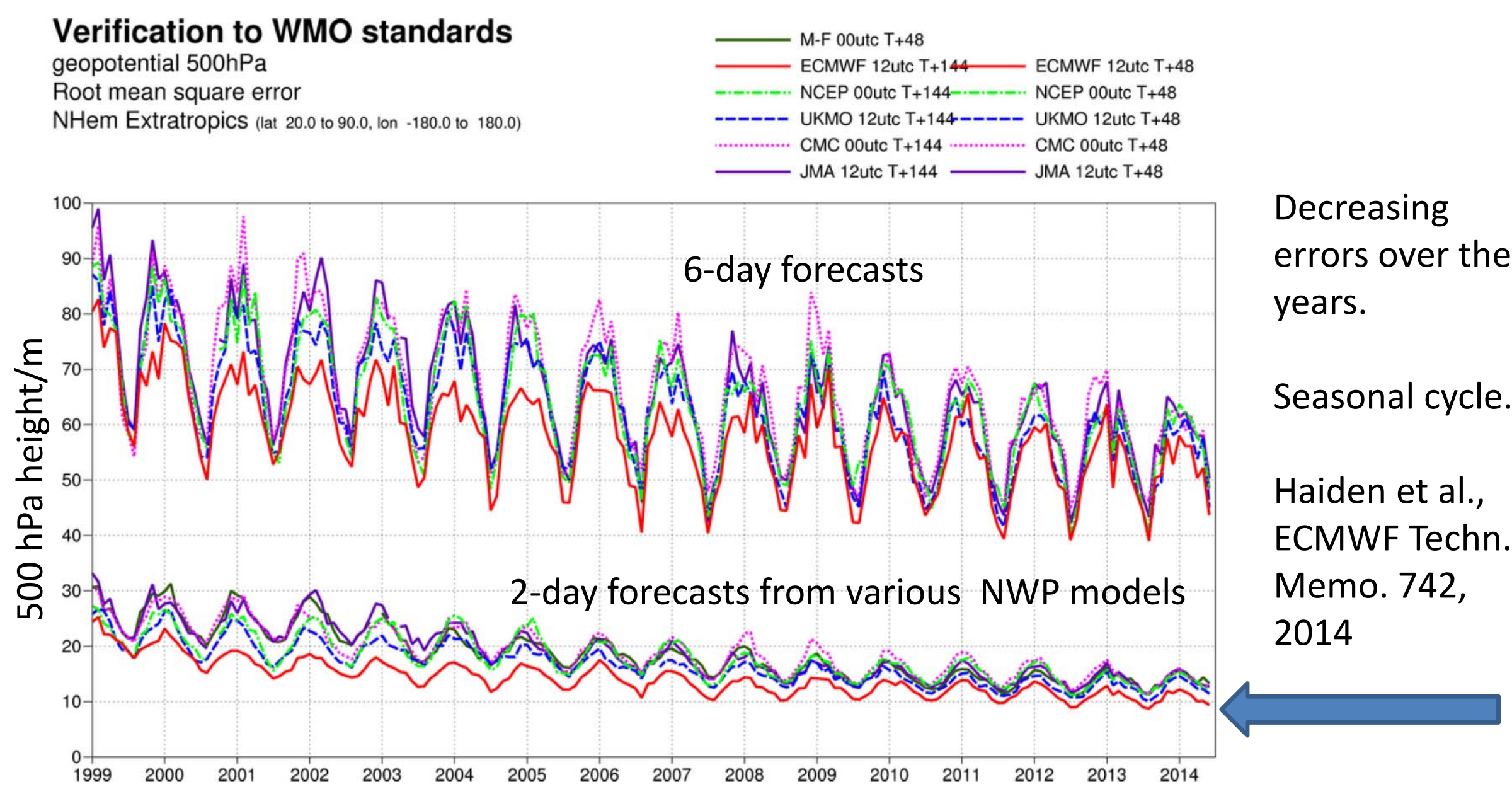

Figure 15: WMO-exchanged scores from global forecast centres. RMS error over northern extratropics for $500 \mathrm{hPa}$ geopotential height ( . In each panel the upper curves show the six-day forecast error and the lower curves show the two-day forecast error. Each model is verified against its own analysis. JMA $=$ Japan Meteorological Agency, $\mathrm{CMC}=$ Canadian Meteorological Centre, UKMO $=$ the UK Meteorological Office, NCEP = U.S. National Centers for Environmental Prediction, M-F = Météo France. 


\section{Same for surface pressure: rms order $1 \mathrm{hPa}$}

\section{Verification to WMO standards}

Mean sea level pressure

Root mean square error

NHem Extratropics (lat 20.0 to 90.0, lon -180.0 to 180.0)
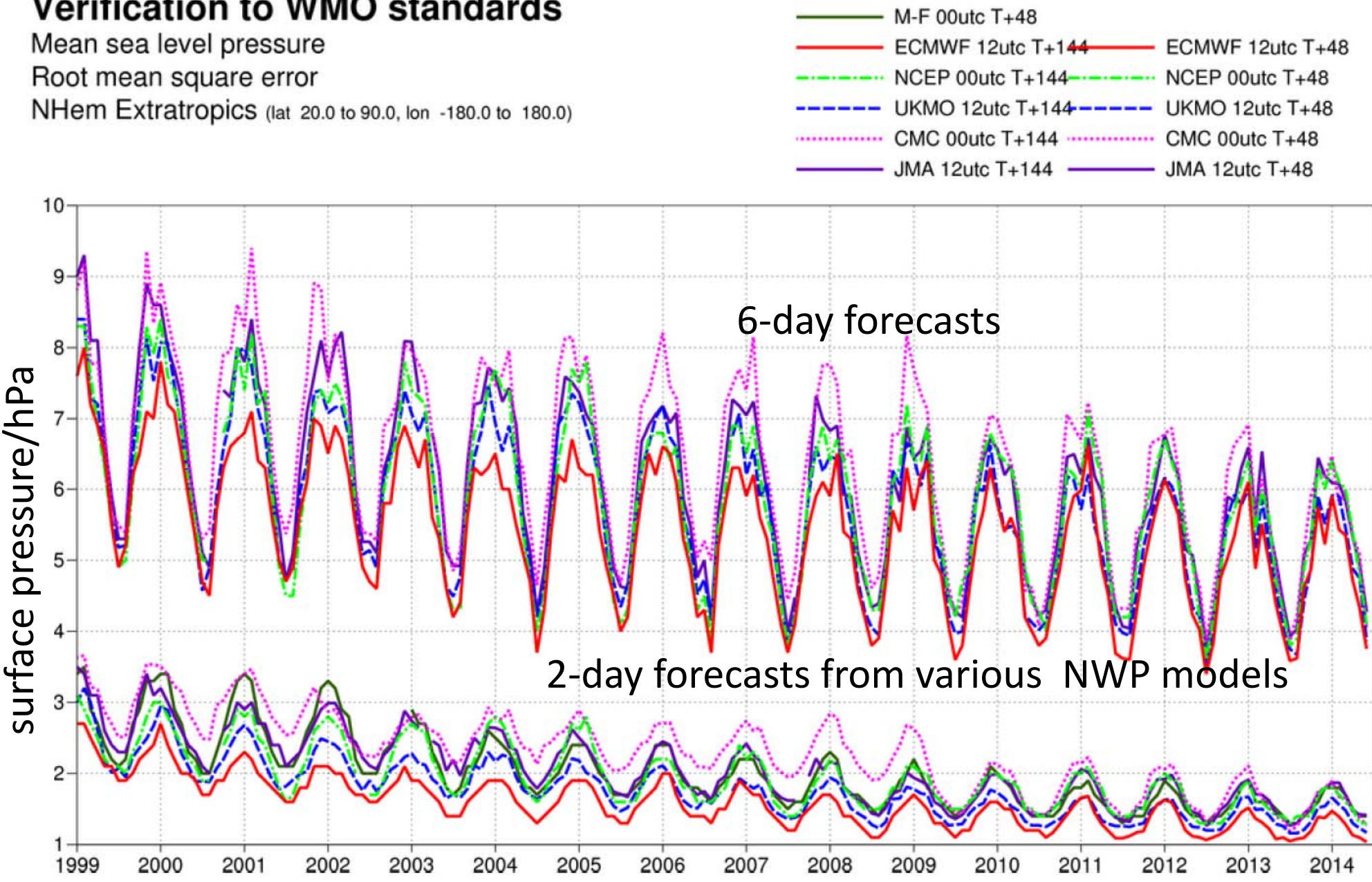

Haiden et al., ECMWF Techn. Memo. 742, 2014

Figure 15: WMO-exchanged scores from global forecast centres. RMS error over northern extratropics for mean sea level pressure (bottom). In each panel the upper curves show the six-day forecast error and the lower curves show the two-day forecast error. Each model is verified against its own analysis. JMA $=$ Japan Meteorological Agency, $\mathrm{CMC}=$ Canadian Meteorological Centre, UKMO $=$ the UK Meteorological Office, NCEP = U.S. National Centers for Environmental Prediction, M-F = Météo France. 


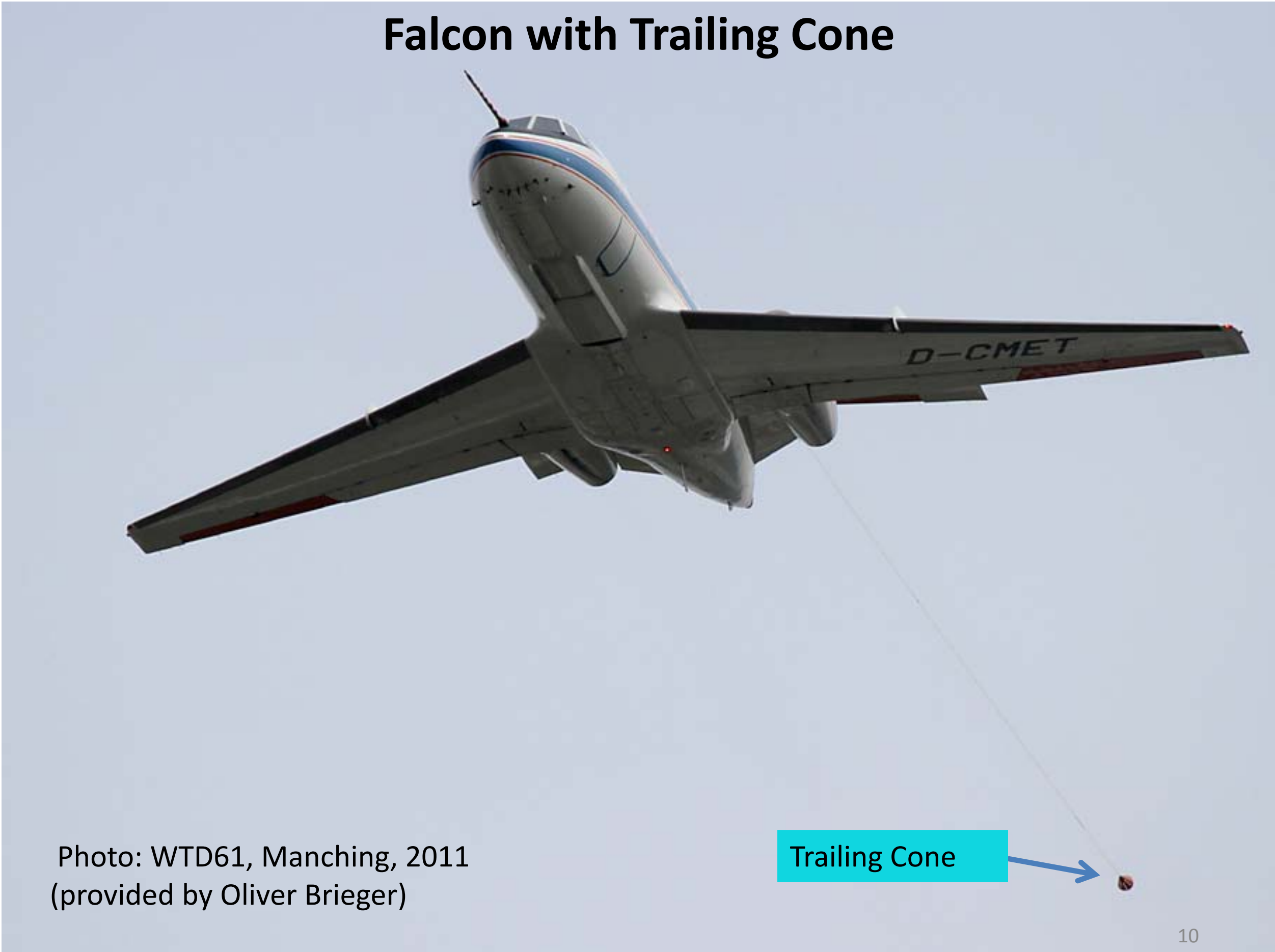




\section{Trailing cone measurements behind DLR aircraft: 159 data points, 20-160 s leg-mean values, Germany}

- HALO p: Weston Aerospace Digital Pressure Module DPM 78851BA, $\Delta \mathrm{p}<0.006 \mathrm{hPa}$

- FALCON p: Rosemount Model 1201FS Sensor with Ruska 7750i reference, $\Delta \mathrm{p}<0.4 \mathrm{hPa}$.

- Altitude above WGS84 with differential GPS, $\Delta z<0.5 \mathrm{~m}$, after post-processing $<0.1 \mathrm{~m}$

- corrected for geoid undulation $\mathrm{N}=\mathrm{h}-\mathrm{z}$ (about 50

\begin{tabular}{|c|c|c|c|}
\hline Aircraft & Region & Date & FL in hft \\
\hline \multirow[t]{5}{*}{ HALO } & ALLGÄU & 15 April 2010 & $350,250,150$ \\
\hline & SAXONY & 22 June 2010 & $\begin{array}{l}430,350,250, \\
40\end{array}$ \\
\hline & ALLGÄU & 24 May 2011 & $\begin{array}{l}150,250,270 \\
, 350,400\end{array}$ \\
\hline & ALLGÄU & $\begin{array}{l}16 \text { September } \\
2011\end{array}$ & $430,350,250$ \\
\hline & ALLGÄU & $\begin{array}{l}23 \text { September } \\
2011\end{array}$ & $\begin{array}{l}290,350,410, \\
150\end{array}$ \\
\hline FALCON & ALLGÄU & 20 May 2011 & $250,330,150$ \\
\hline
\end{tabular}
m)
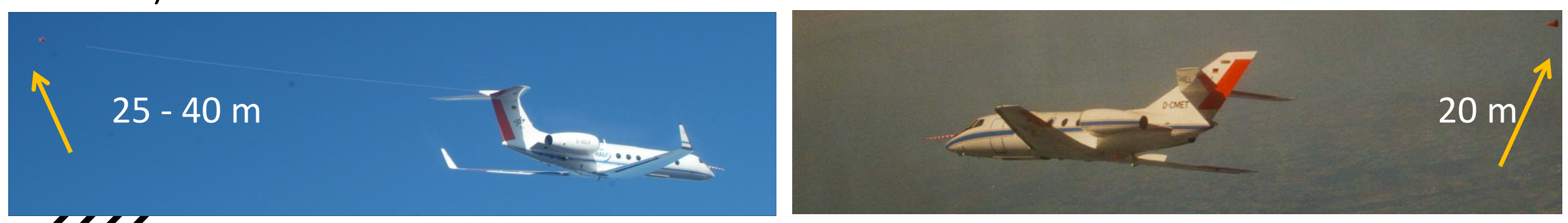


\section{TC pressure measurement error from flyby maneuvers}

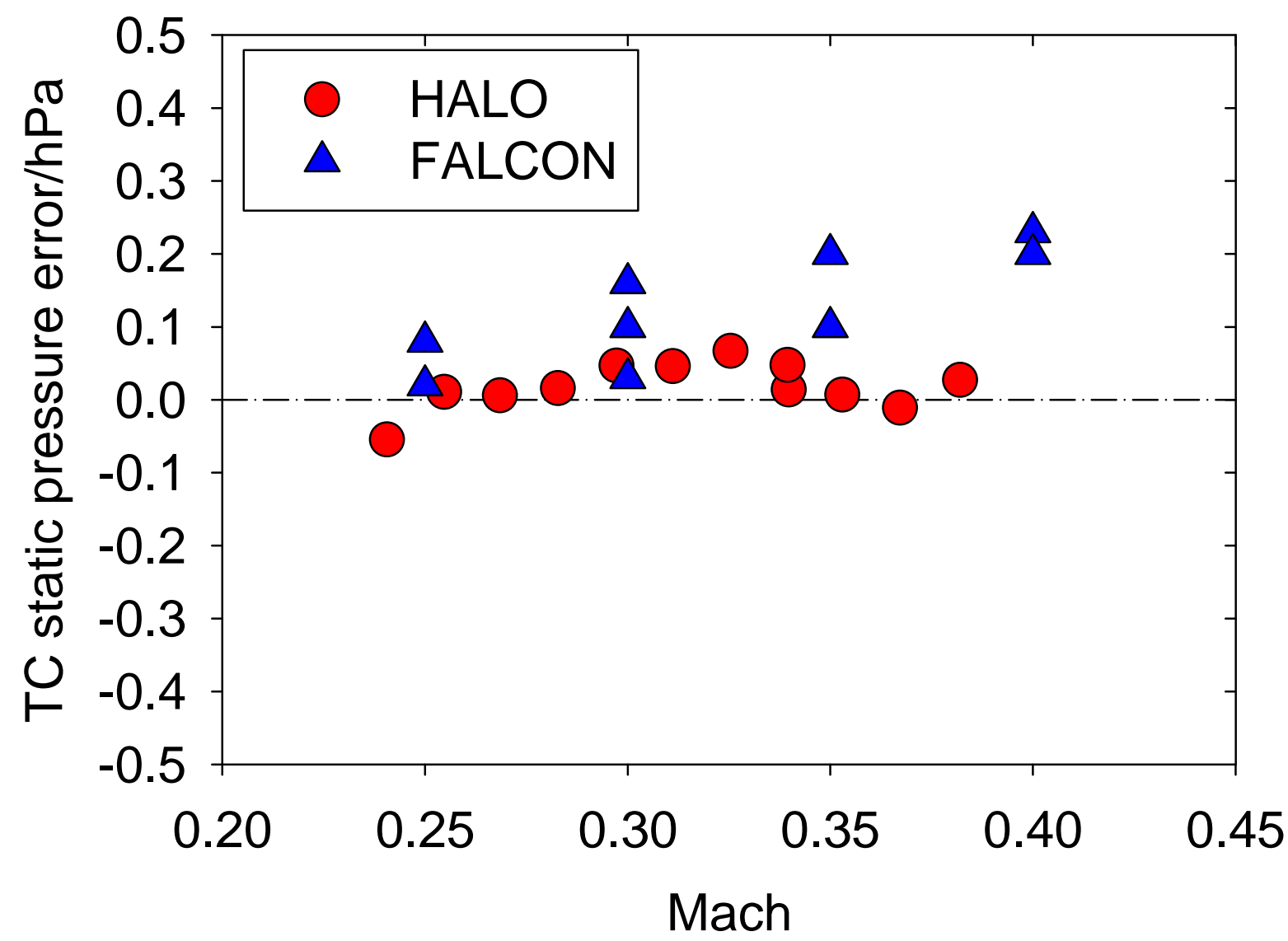

accuracy:

$\Delta \mathrm{p}=0.12 \mathrm{hPa}$ for HALO

$\Delta p=0.5 \mathrm{hPa}$ for Falcon

corresponding to

$\Delta \mathrm{z}=1 \mathrm{~m}$ for HALO

$\Delta \mathrm{p}=4 \mathrm{~m}$ for Falcon

at ground

Falcon:

upper bound from

Gaussian error

propagation

Differences between trailing cone pressure sensor reading and hydrostatically corrected pressure on the ground for HALO and Falcon 


\section{NWP analysis:}

- NWP data from the Integrated Forecasting System(IFS) of the European Centre for

$$
p_{k+1 / 2}=a_{k+1 / 2}+b_{k+1 / 2} p_{s f_{c}}, k=0, \ldots, \mathrm{K} .
$$

Medium-Range Weather Forecasts (ECMWF)

- $0.25^{\circ}$ horizontal resolution

- 91 layers $(\Delta \mathrm{p} \approx 14 \mathrm{hPa}, \Delta \mathrm{z} \approx 400 \mathrm{~m}$ at

$$
\begin{aligned}
& \Phi=\int_{0}^{z} g d z \\
& \Phi_{k+1 / 2}=\Phi_{k-1 / 2}-\int_{p_{k-1 / 2}}^{p_{k+1 / 2}} \frac{R T_{V}}{p} d p \\
& \cong \Phi_{k-1 / 2}-R T_{V, k} \ln \left(\frac{p_{k+1 / 2}}{p_{k-1 / 2}}\right)
\end{aligned}
$$

- vertically in $\log (p)$

- Somigliana-type gravity formula, height dependence from DoD/NIMA TR8350.2

- Including surface gravity anomalies $\delta g$ from Earth Gravitational Model 2008 (EGM2008)

$$
\begin{aligned}
& g=9.80665 \mathrm{~m} \mathrm{~s}^{-2} \\
& \text { or } \\
& g=\gamma_{z}(z, \phi)+\delta g(\phi, \lambda)
\end{aligned}
$$

- assuming small horizontal wind

for $\mathrm{z}<13.5 \mathrm{~km}: \quad \Delta \mathrm{g} / \mathrm{g}<0.43 \%$.

gravity varies due to the distance to Earth's center, Earth's rotation and local gravity anomalies from crust density variations 


\section{Gravity is altitude dependent}

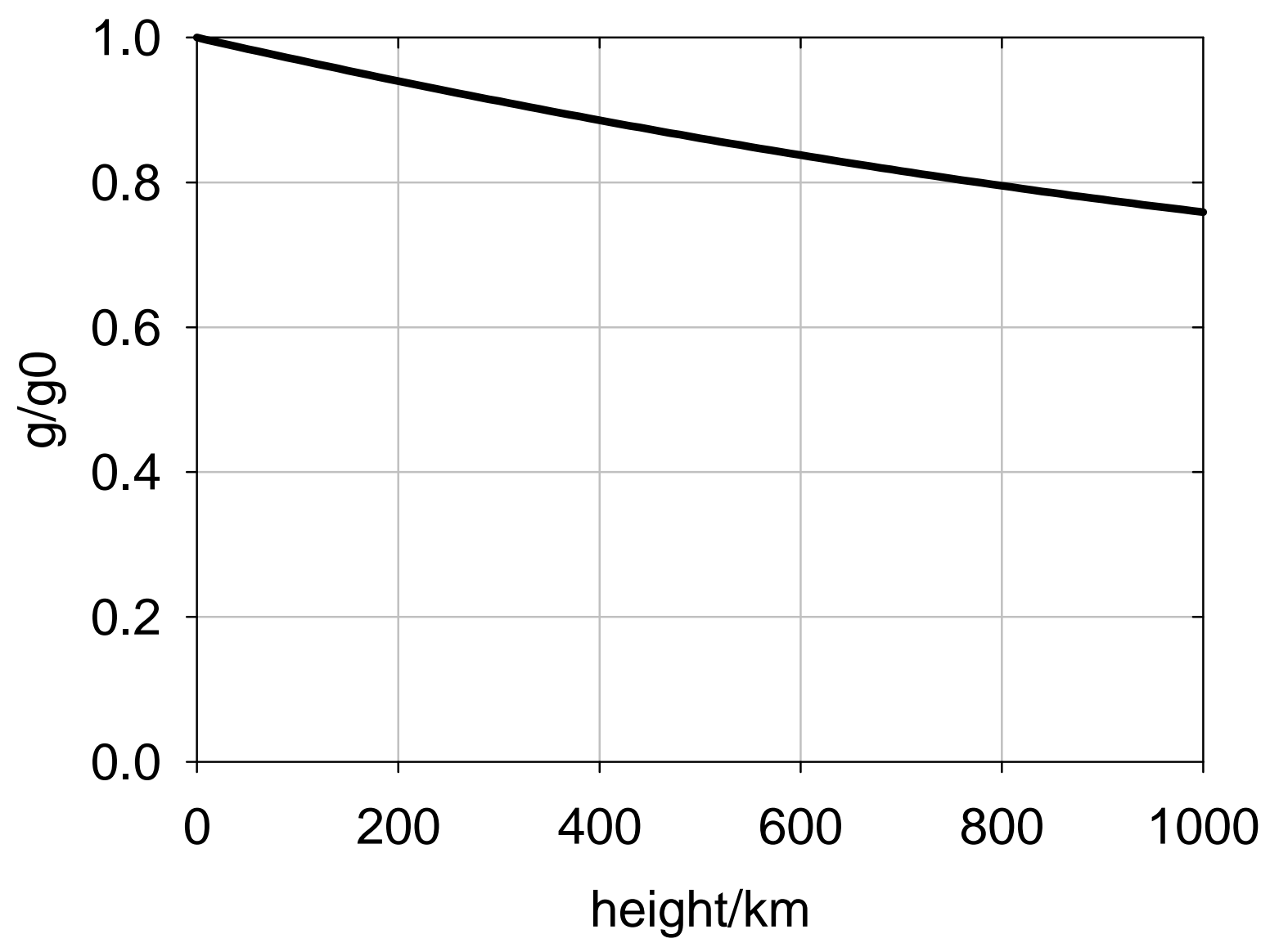

at FL 450, $13.7 \mathrm{~km}$ :

$\Delta \mathrm{g} / \mathrm{g}=0.4 \%$

4 


\section{Deviation from sphere and rotation dependent gravity variability are connected}

(Spheroidal and spherical geopotential approximations)

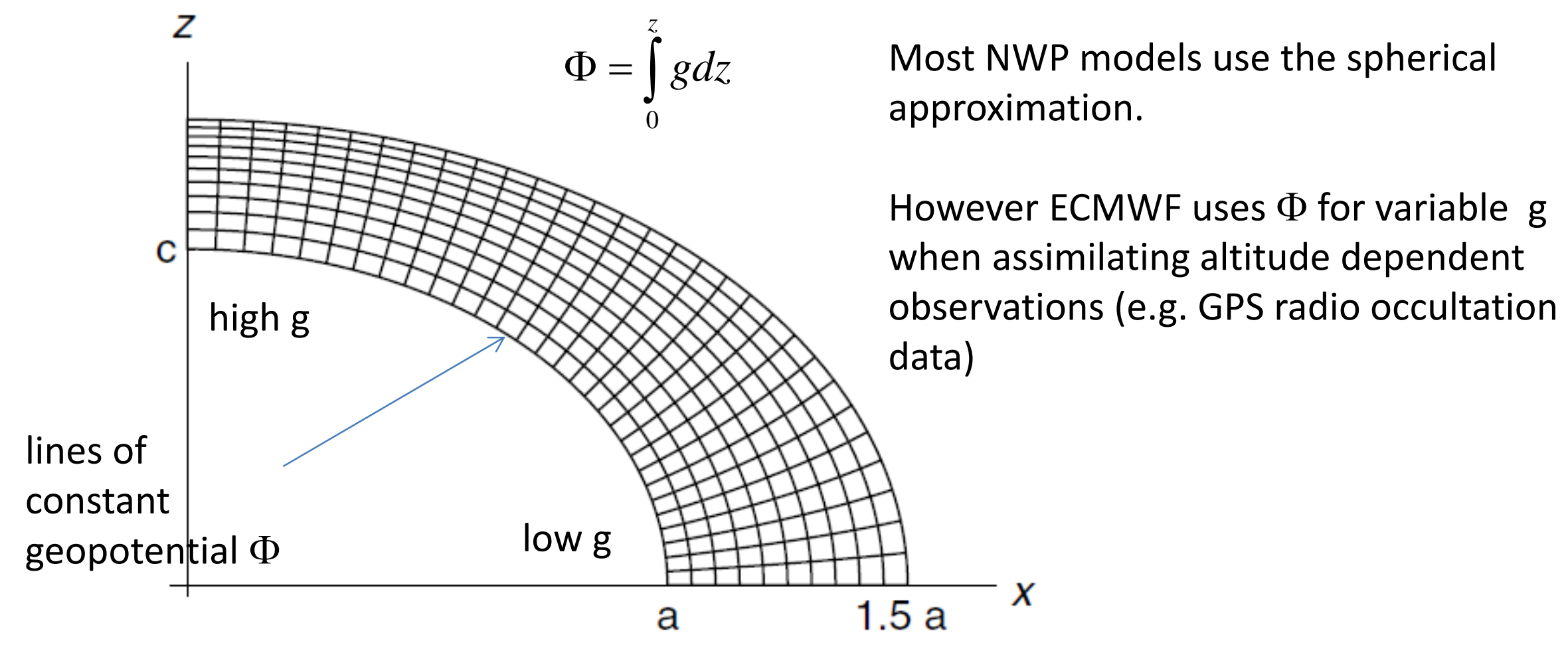

Bénard (QJRMS, 2014)

see also Staniforth (QJRMS, 2014) 


\section{Gravity is latitude and longitude dependent}

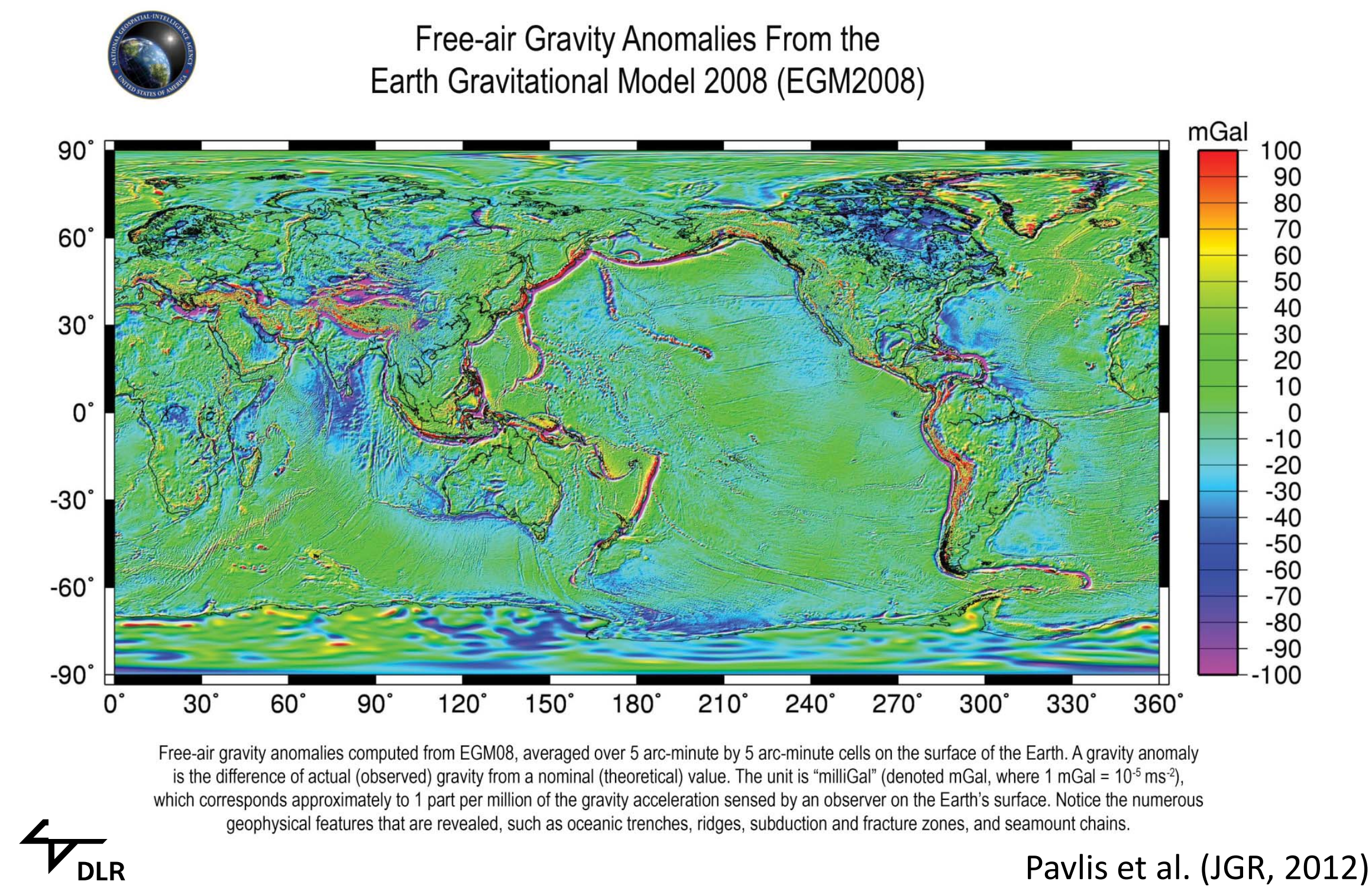




\section{Results}

159 test points from 6 days with 2 aircraft (Halo $\mathrm{H}$ and Falcon F) for FL $50-430 \mathrm{hft}$

$\Delta \mathrm{p}, \Delta \mathrm{z}$ computed for constant $(\mathrm{g}=\mathrm{c})$ gravity

Max deviations:

$0.75 \mathrm{hPa}, 27 \mathrm{~m}$

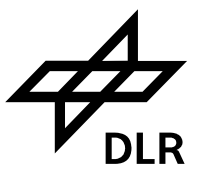

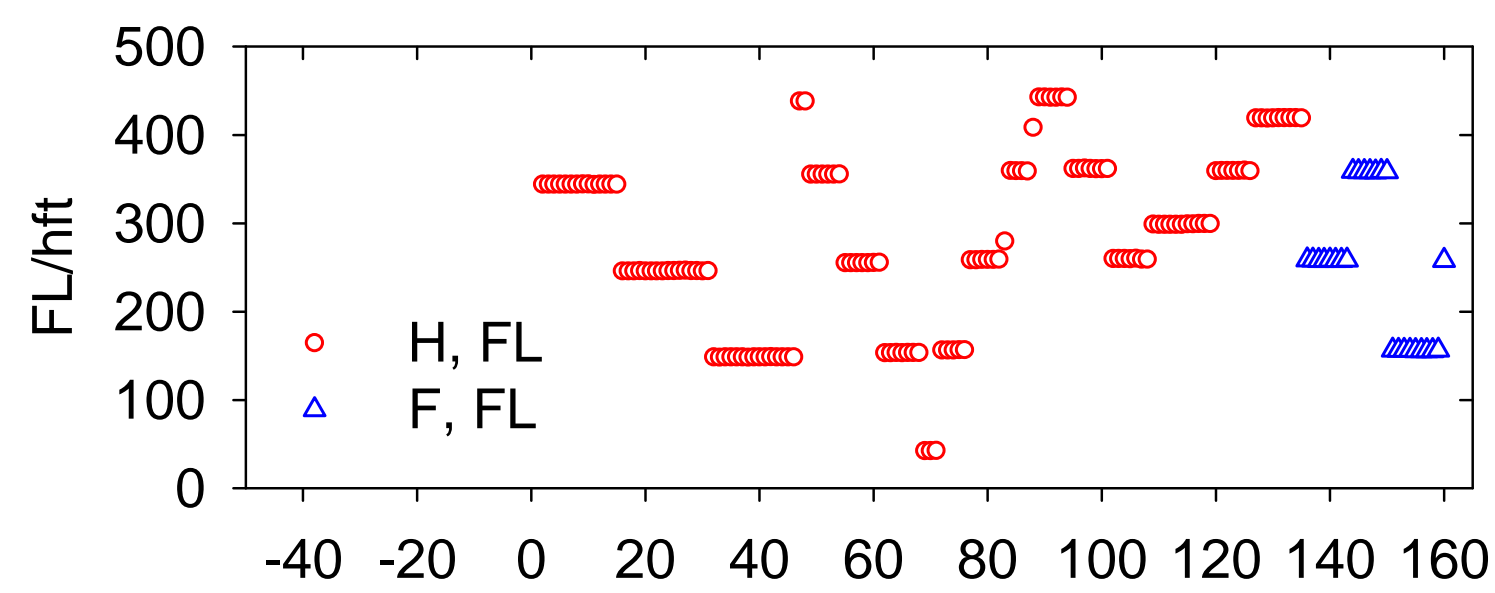
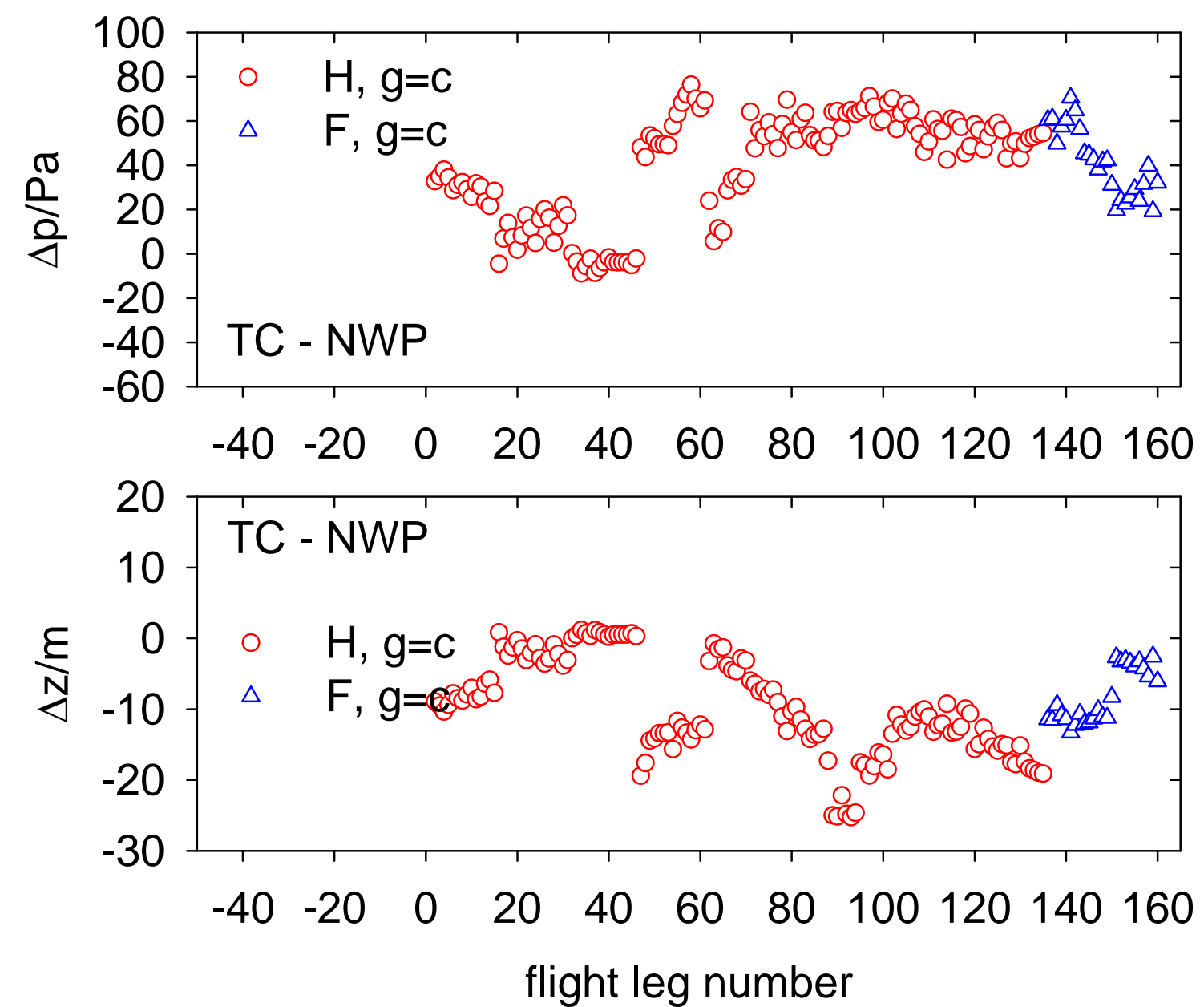


\section{Results}

159 test points from 6 days with 2 aircraft (Halo $\mathrm{H}$ and Falcon F) for FL $50-430 \mathrm{hft}$

$\Delta p, \Delta z$ computed for constant $(\mathrm{g}=\mathrm{c})$ and variable $(\mathrm{g}=\mathrm{v})$ gravity

Max deviations:

(0.75 hPa, $27 \mathrm{~m}$ )

$0.68 \mathrm{hPa}, 9 \mathrm{~m}$

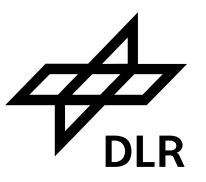

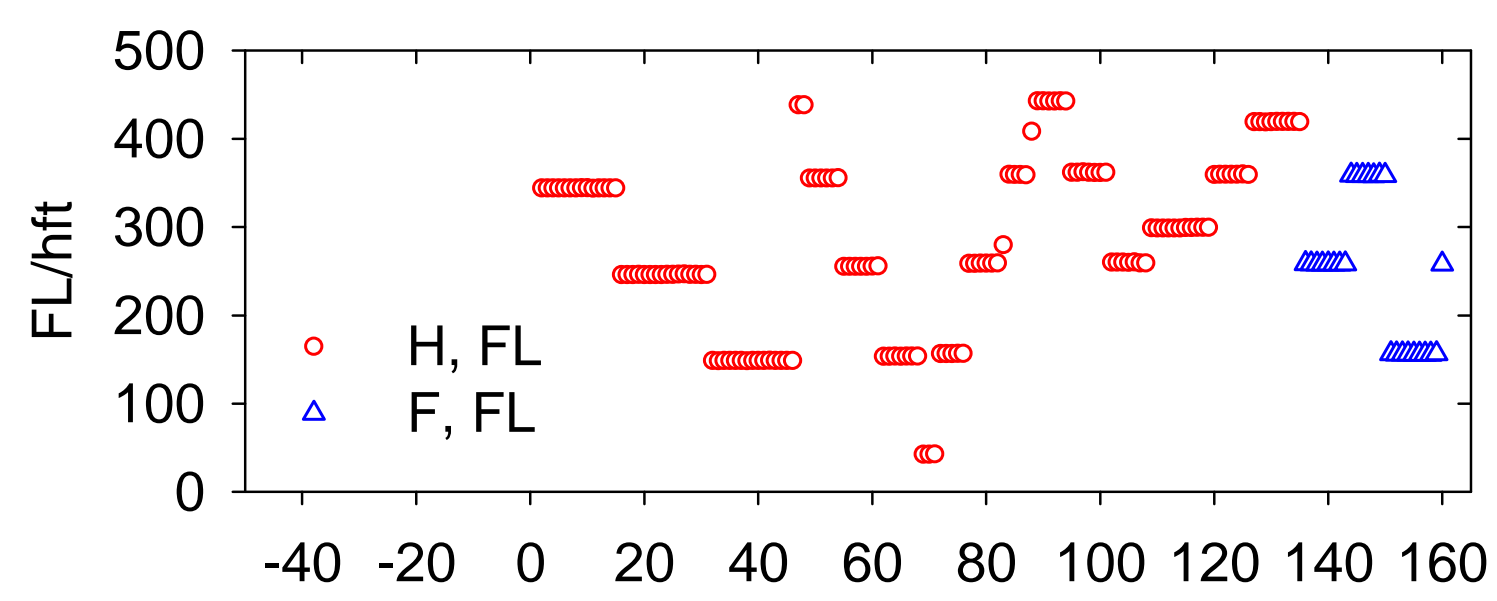
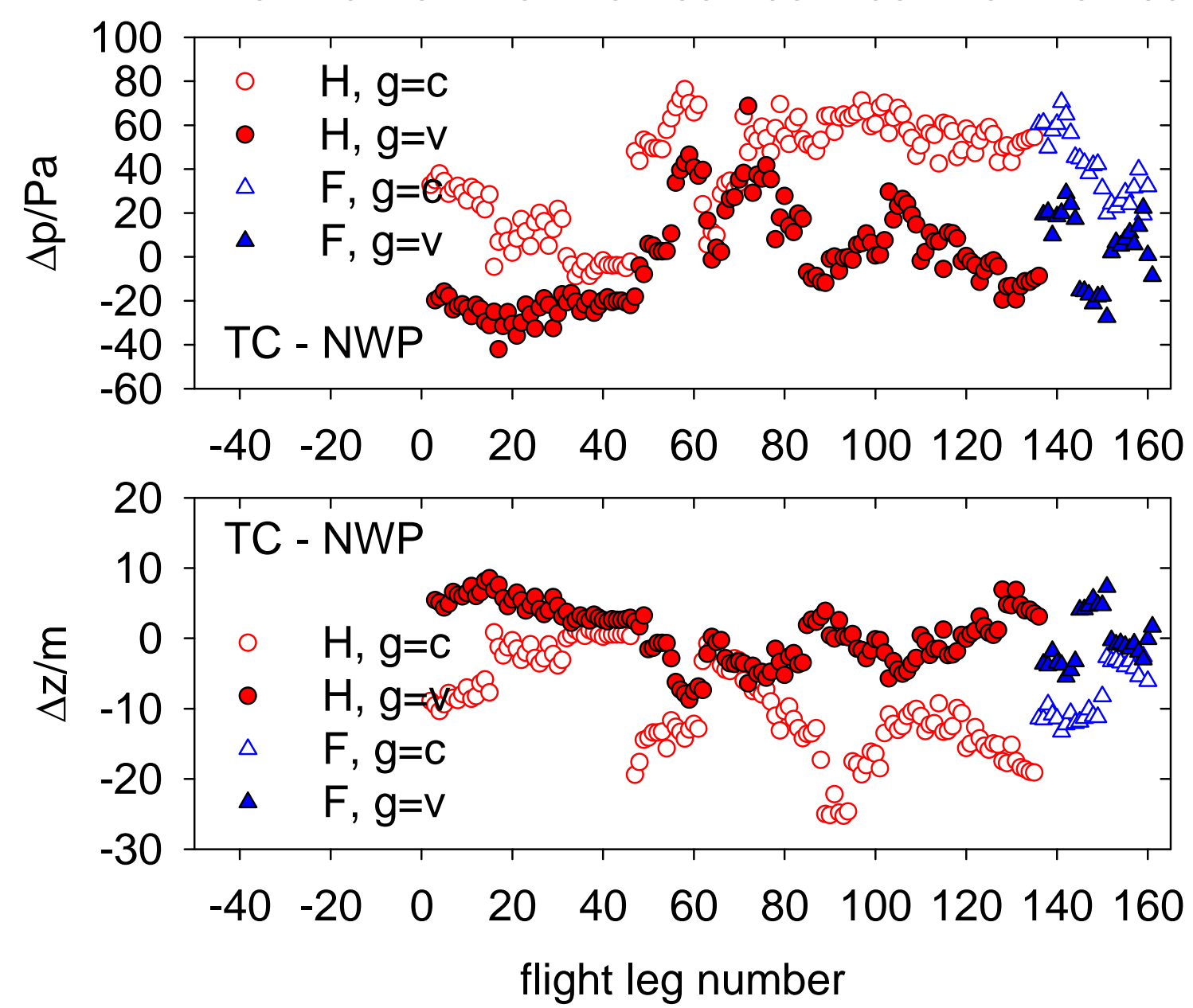
Flight level

dependence:

Significantly

smaller deviations

of $\Delta z$ and $\Delta p$

for variable $g$

than for

constant g
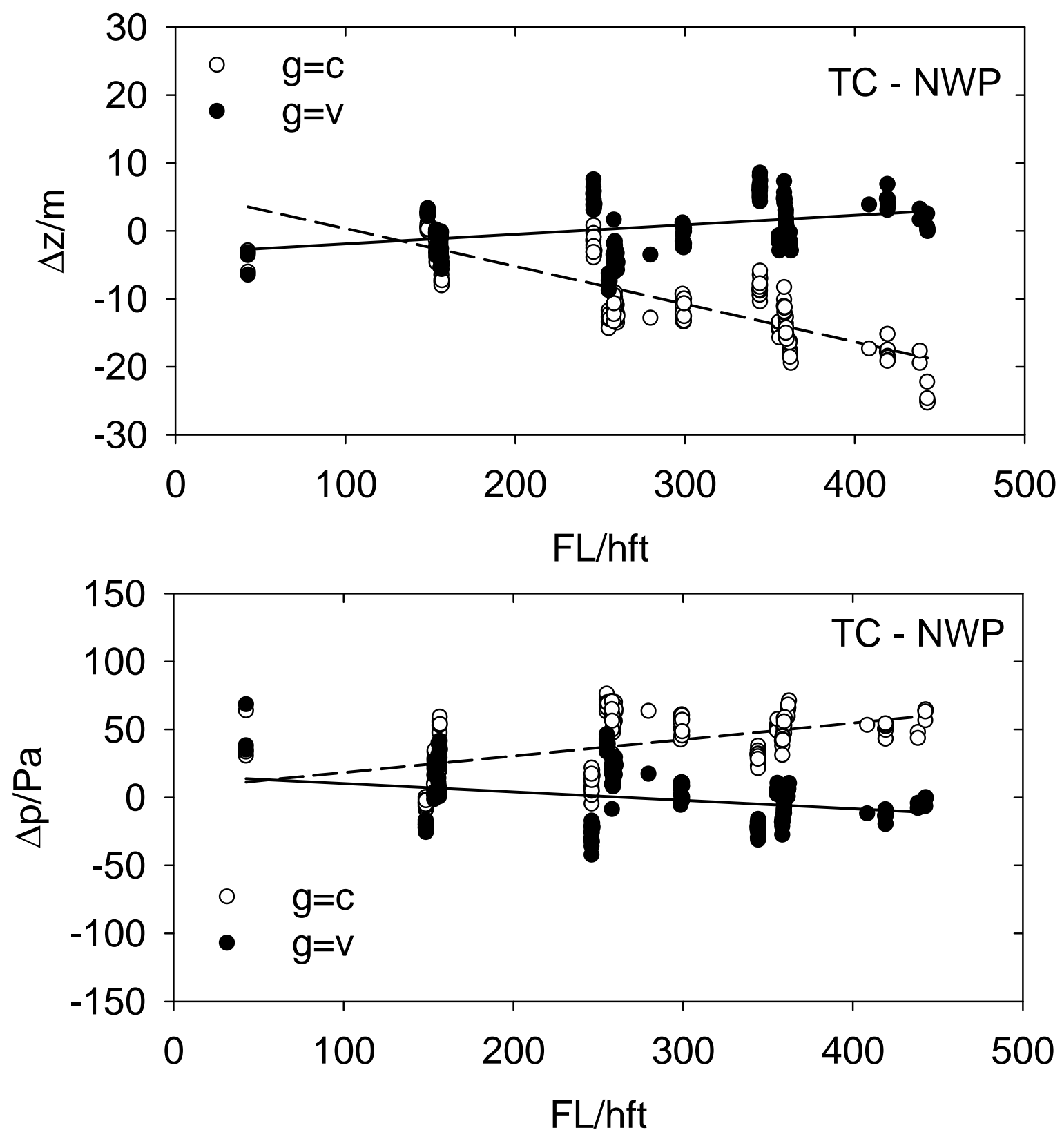


\section{Mean deviations}

\begin{tabular}{l|l|l} 
gravity model & $\Delta \mathrm{z} / \mathrm{m}$ & $\Delta \mathrm{p} / \mathrm{Pa}$ \\
\hline $\mathrm{g}=9.80655 \mathrm{~m} \mathrm{~s}^{-2}$ & $-9.5 \pm 4.6$ & $39.90 \pm 16.2$ \\
$\mathrm{~g}=\gamma_{2}(\phi, \lambda)+\Delta \mathrm{g}$ & $0.6 \pm 2.8$ & $-0.8 \pm 14.9$
\end{tabular}

not only the mean errors but also the standard deviations are smaller for variable $g$ than constant g! 


\section{Low sensitivity to flight level, FL}

Significantly smaller deviations for variable $g$ than for constant $g$

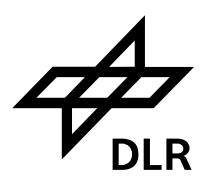

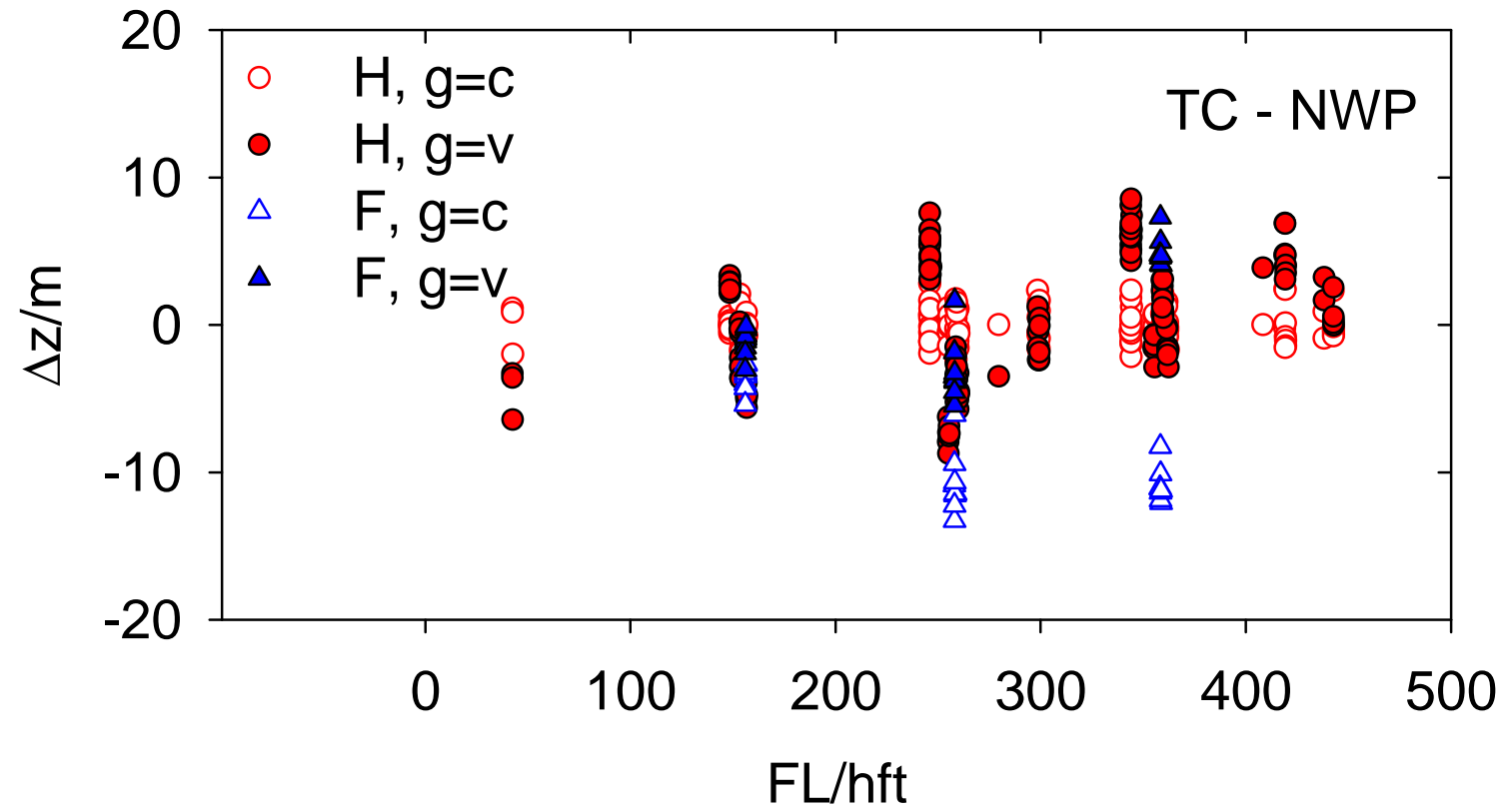

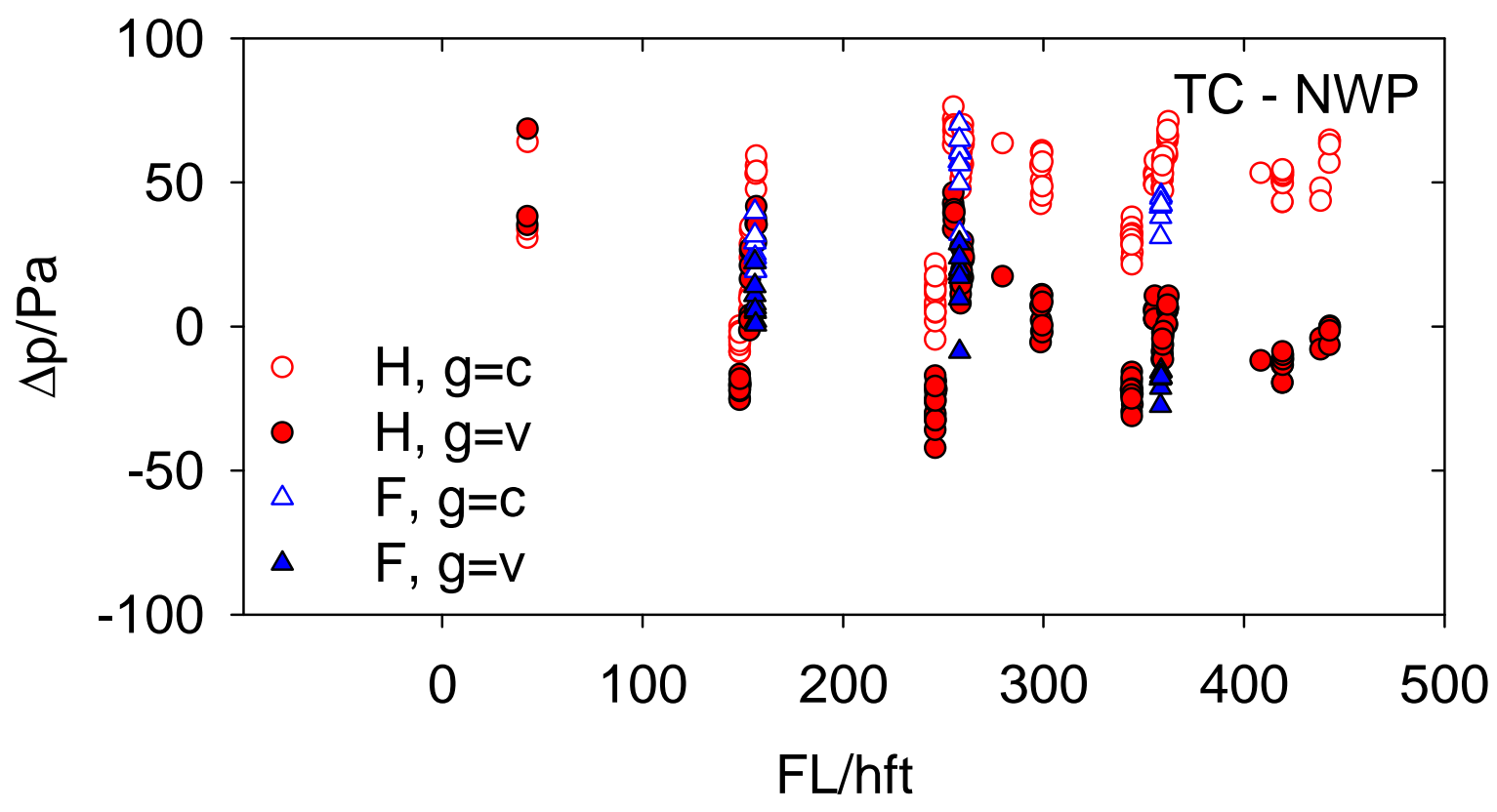




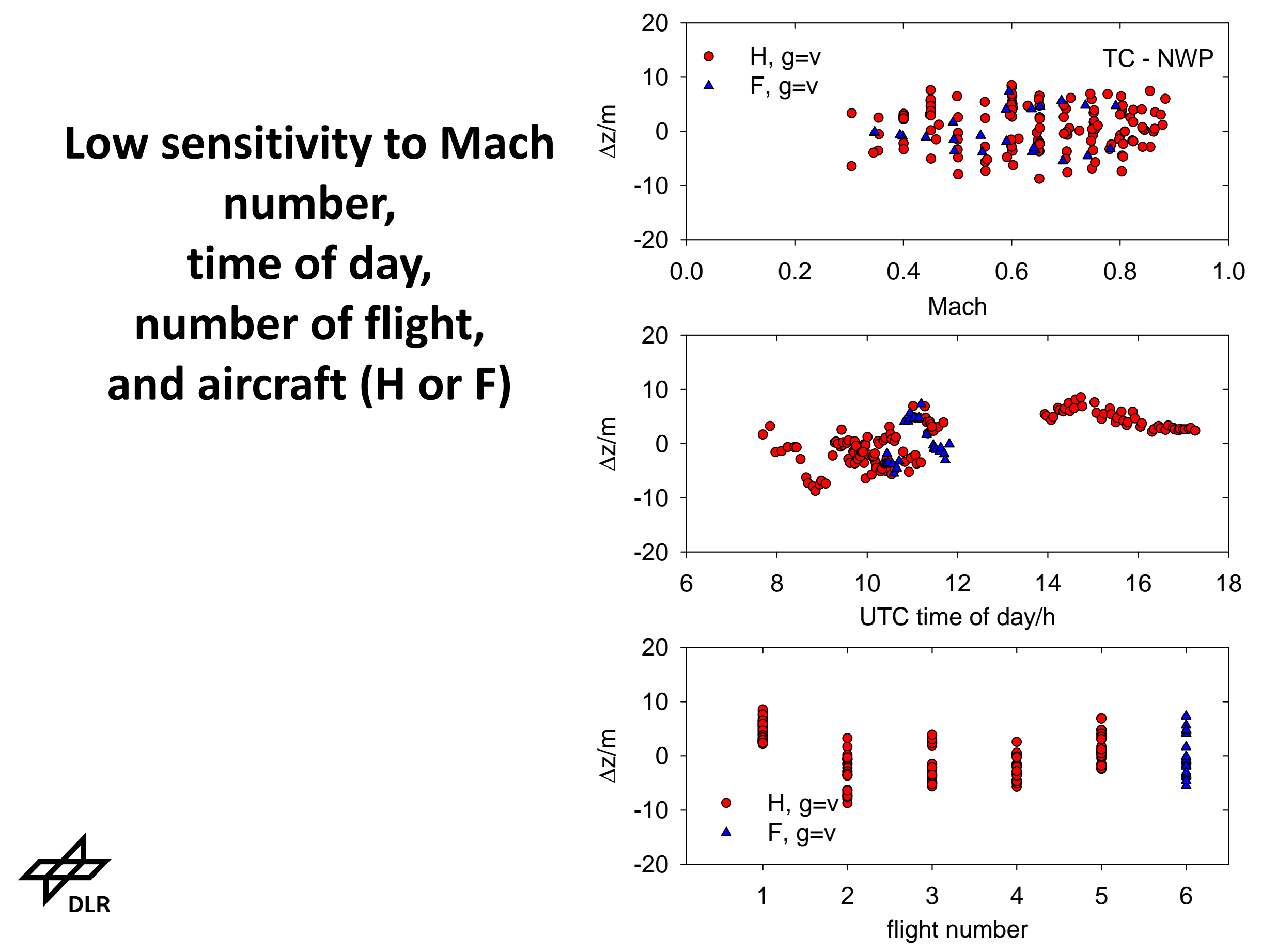


Low random errors (deviations of single values from average over all legs at constant FL)

$$
\begin{aligned}
\Delta z^{\prime} & <3 \mathrm{~m}, \\
\Delta \mathrm{p}^{\prime} & <20 \mathrm{~Pa}
\end{aligned}
$$
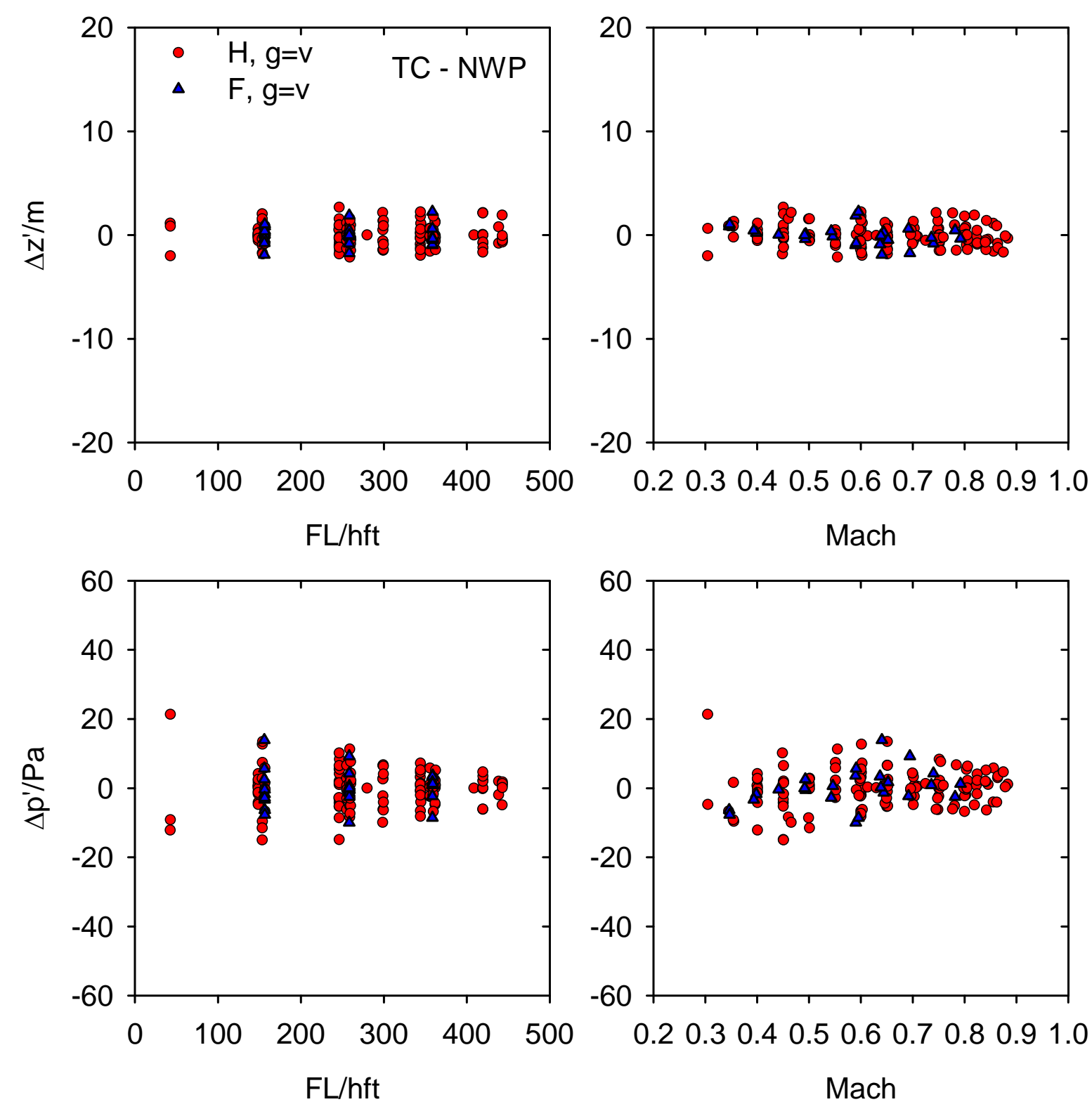


\section{Random errors}

(deviations of single values from average over all legs at constant $\mathrm{FL}$ )

Importance of gravity and DGPS/INU postprocessing

\begin{tabular}{|c|c|c|}
\hline g model & $\sigma\left(\Delta \mathrm{p}^{\prime}\right)$ & $\sigma\left(\Delta \mathrm{z}^{\prime}\right)$ \\
\hline $\mathrm{g}=9.80665 \mathrm{~m} \mathrm{~s}^{-2}$ & HALO & \\
\hline $\mathrm{g}=\gamma_{\mathrm{z}}$ & $5.63 \mathrm{~Pa}$ & $1.10 \mathrm{~m}$ \\
\hline $\mathrm{g}=\gamma_{\mathrm{t}} \Delta \mathrm{g}$ & $5.40 \mathrm{~Pa}$ & $1.04 \mathrm{~m}$ \\
\hline online DGPS & $5.33 \mathrm{~Pa}$ & $1.02 \mathrm{~m}$ \\
\hline
\end{tabular}




\section{Reminder: JAA Administrative \& Guidance Material Section One: General Part 3: Temporary Guidance Leaflets}

LEAFLET NO 6: Revision 1

GUIDANCE MATERIAL ON THE APPROVAL OF AIRCRAFT AND OPERATORS FOR FLIGHT IN AIRSPACE ABOVE FLIGHT LEVEL 290 WHERE A 300M (1,000 FT) VERTICAL SEPARATION MINIMUM IS APPLIED

Altimetry System Error (ASE) The difference between the pressure altitude displayed to the flight crew when referenced to the International Standard Atmosphere ground pressure setting (1013.2 hPa $/ 29.92 \mathrm{in.Hg}$ ) and free stream pressure altitude.

7.3.2 Assessment of ASE, whether based on measured or predicted data will need to consider subparagraphs (a) to (d) of 7.3.1. The effect of item (d) as a variable can be eliminated by evaluating ASE at the most adverse flight condition in an RVSM flight envelope.

7.3.3 The criteria to be met for the Basic envelope are:

(a) At the point in the envelope where the mean ASE reaches its largest absolute value that value should not exceed $25 \mathrm{~m}(80 \mathrm{ft})$;

(b) At the point in the envelope where absolute mean ASE plus three standard deviations of ASE reaches its largest absolute value, the absolute value should not exceed $60 \mathrm{~m}$ $(200 \mathrm{ft})$. 


\section{Results}

$\Delta z$ within the limits relevant for RVSM operation

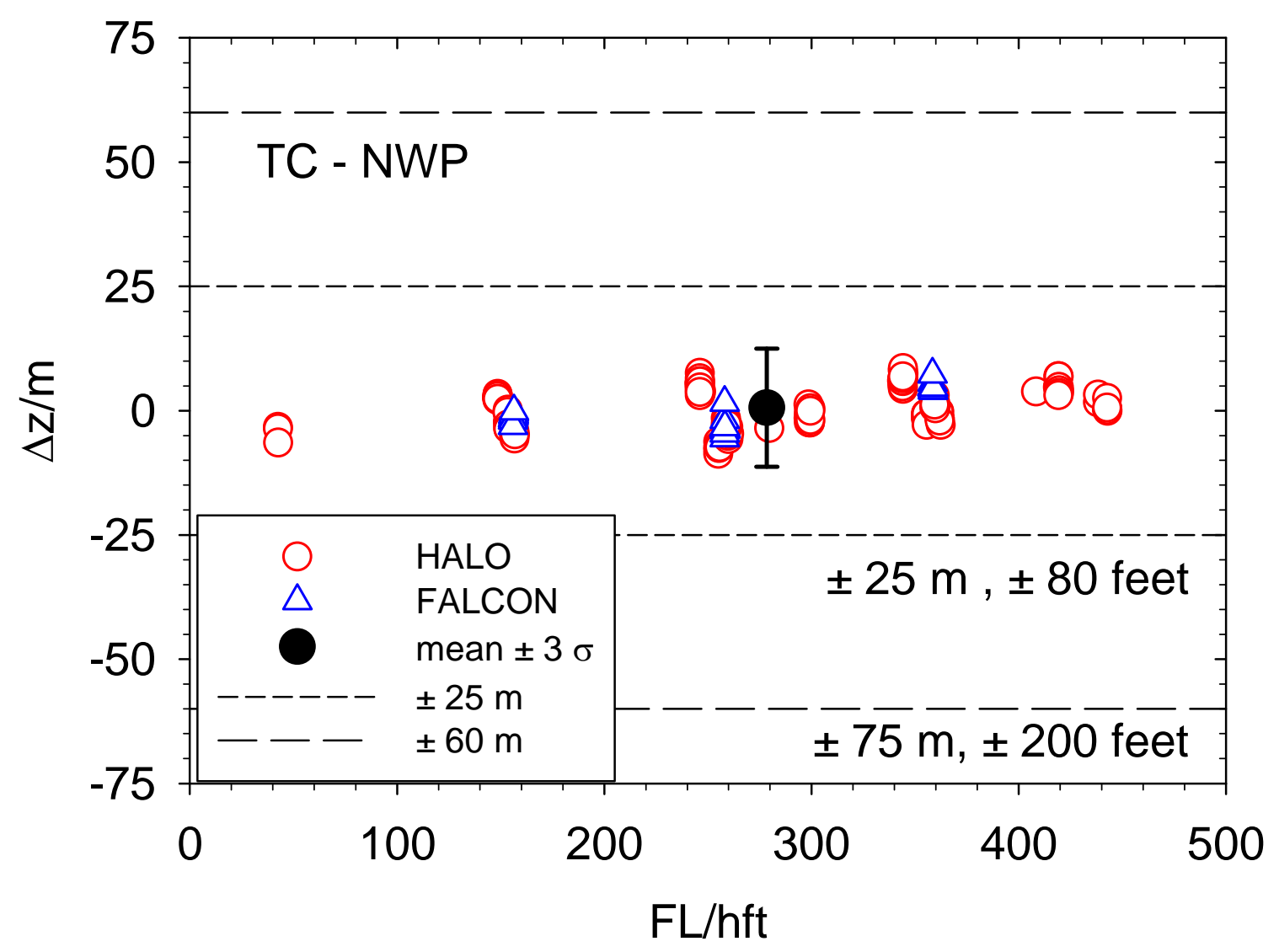

क्ष 


\section{Conclusions}

- Accuracy of static pressure and height assessed with TC pressure and DGPS altitude measurements and pressure/geopotential from ECMWF

- essential: post-processed DGPS altitude data and variable g

- $\Delta z<9 m$ for 159 data points from six flights

- Mean temperature error $<0.1 \mathrm{~K}$ below flight levels.

- Agreement noteworthy for aviation and meteorology.

- Ellipsoidal geoid and variable gravity important also for NWP

- Geopotential is more sensitive to $\Delta \mathrm{g}$ than to $\Delta$ humidity in this test

- Open: prediction of most suitable test conditions, other NWP system data

- Further tests at DLR, Institute of Flight Systems, Braunschweig, tbp

- NWP data and the analysis method offer the potential for static pressure calibration and for control of the height keeping performance

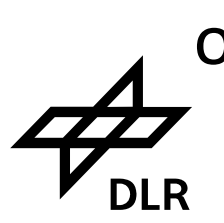
of aircraft during operation. 


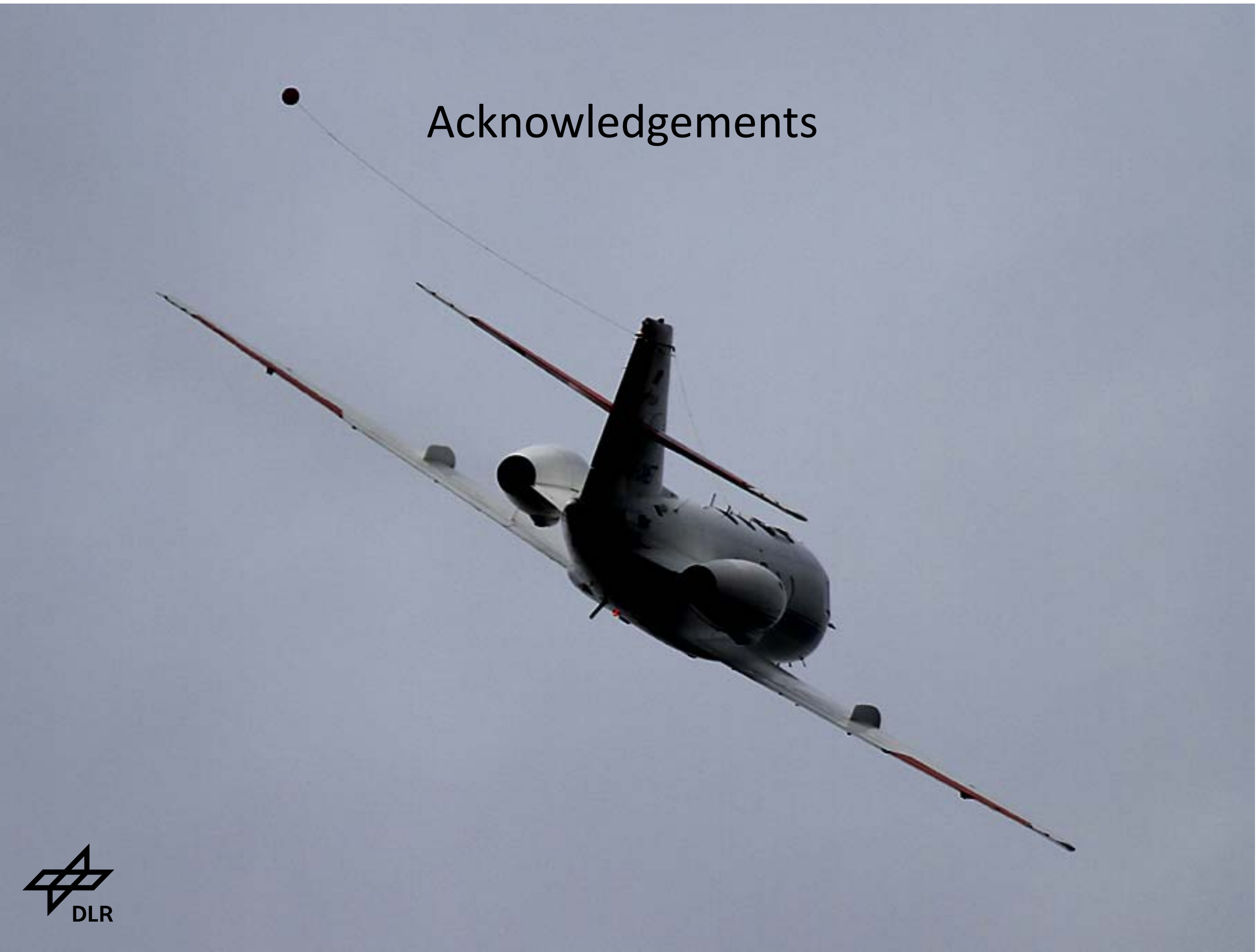




\section{Acknowledgements}

- Support from DLR Institute of Flight Systems in performing towèr flybys with trailing cone measurements with the Fa/con and position data postprocessing:

- ECMWF data were orovided Whin the ECMWF special project "Support Toolfor HALO ÍMissions".

- Thanks to all supporting partners, in particular for support of FALCON and HALO operations

- Thanks to Martin Wirth and Oliver Brieger for helpful comments 


\section{Comparison of Static Pressure from Aircraft Trailing Cone Measurements and Numerical Weather Prediction Analysis}

Andreas Giez, Christian Mallaun, Martin Zöger,

\section{Andreas Dörnbrack and Ulrich Schumann}

German Aerospace Center,

Flight Experiments and Institute of Atmospheric Physics,

Oberpfaffenhofen, Germany

- Height-keeping performance of aircraft is a key element in ensuring safe operations in RVSM airspace.

- Accurate pressure -geopotential relation is fundamental for meteorology

- We compare Trailing Cone (TC) and Numerical Weather Prediction (NWP) data

- The accuracy of the TC and NWP data is useful for control of height keeping performance and assessment of weather analysis 


\section{DGPS data corrected for Geoid undulation, $\mathbf{N}=\mathbf{h}-\mathbf{z}$}

Difference between altitude $h$ relative to WGS84 and height $z$ above MSL.

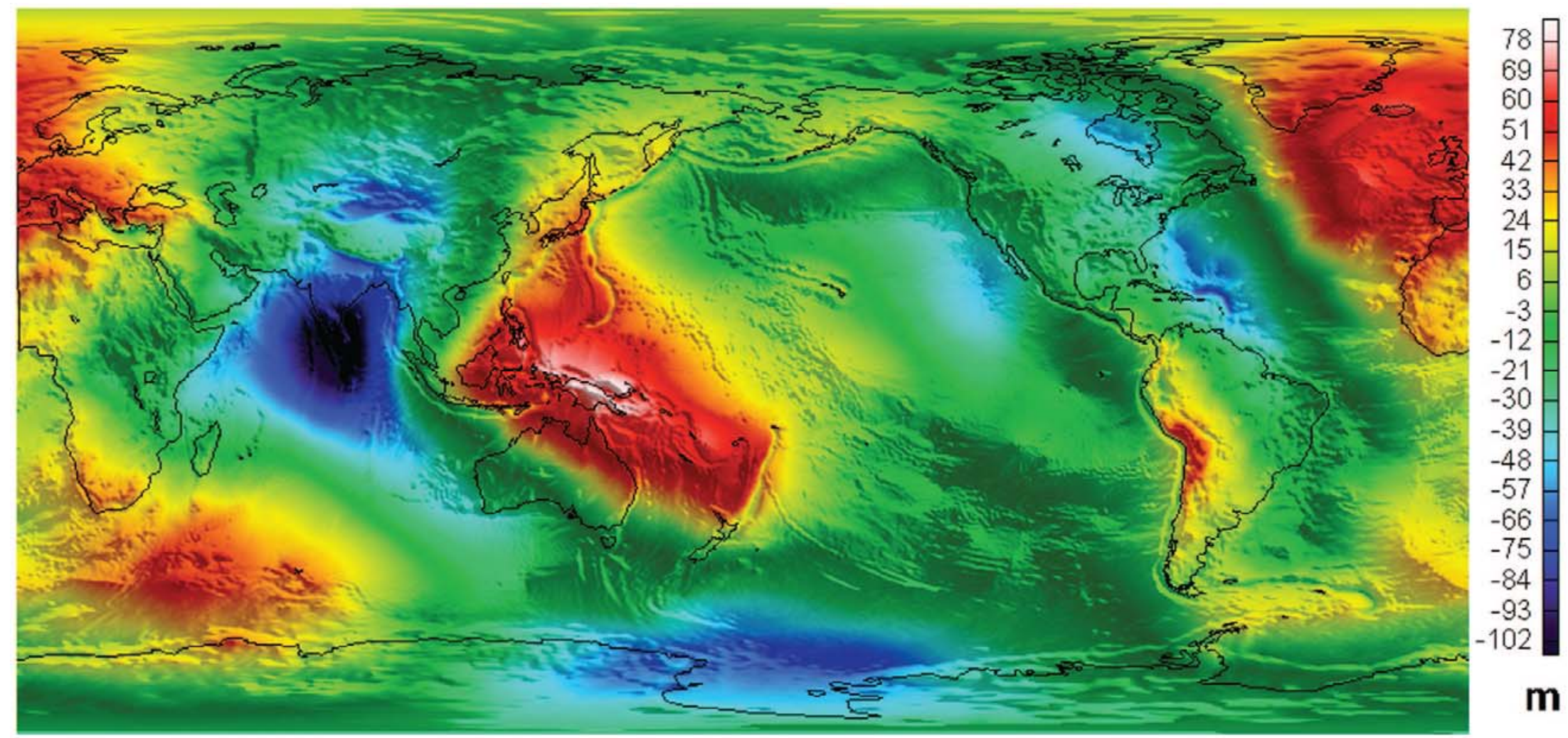

Global geoid undulations (Lemoine et al., 1998).

The undulations range from $-107 \mathrm{~m}$ to $85 \mathrm{~m}$. 


\section{Geoid undulation}

The height $\mathrm{z}$ above MSL differs from the altitude $\mathrm{h}$ relative to WGS84 by about $50 \mathrm{~m}$ over the European continent. The altitude difference is known as geoid undulation $\mathrm{N}, \quad \mathrm{N}=\mathrm{h}-\mathrm{z}$.

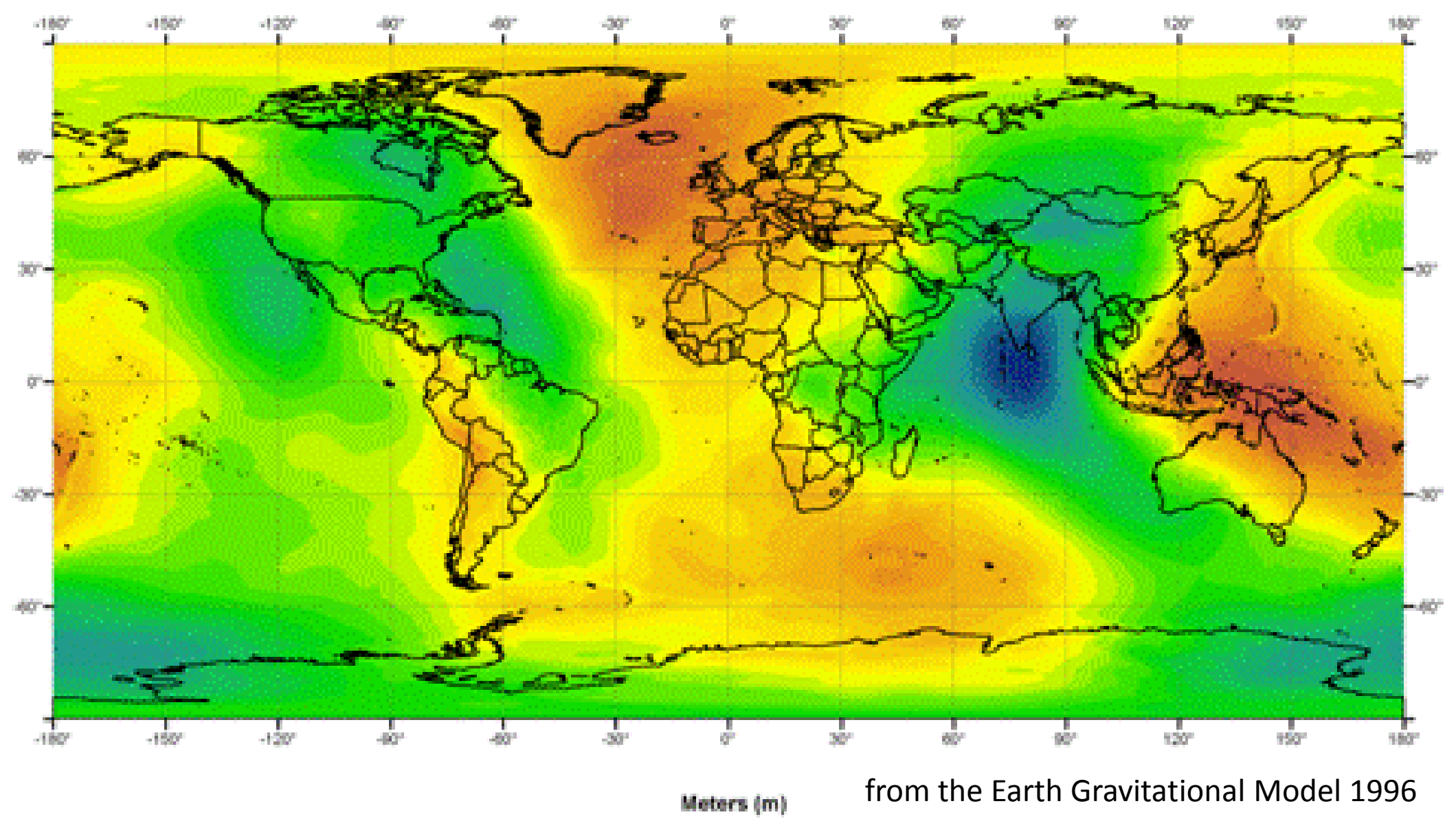




\section{Results}

159 test points from 6 days with 2 aircraft (Halo $\mathrm{H}$ and Falcon F) for FL $50-430$ hft

unacceptable, missing undulation correction
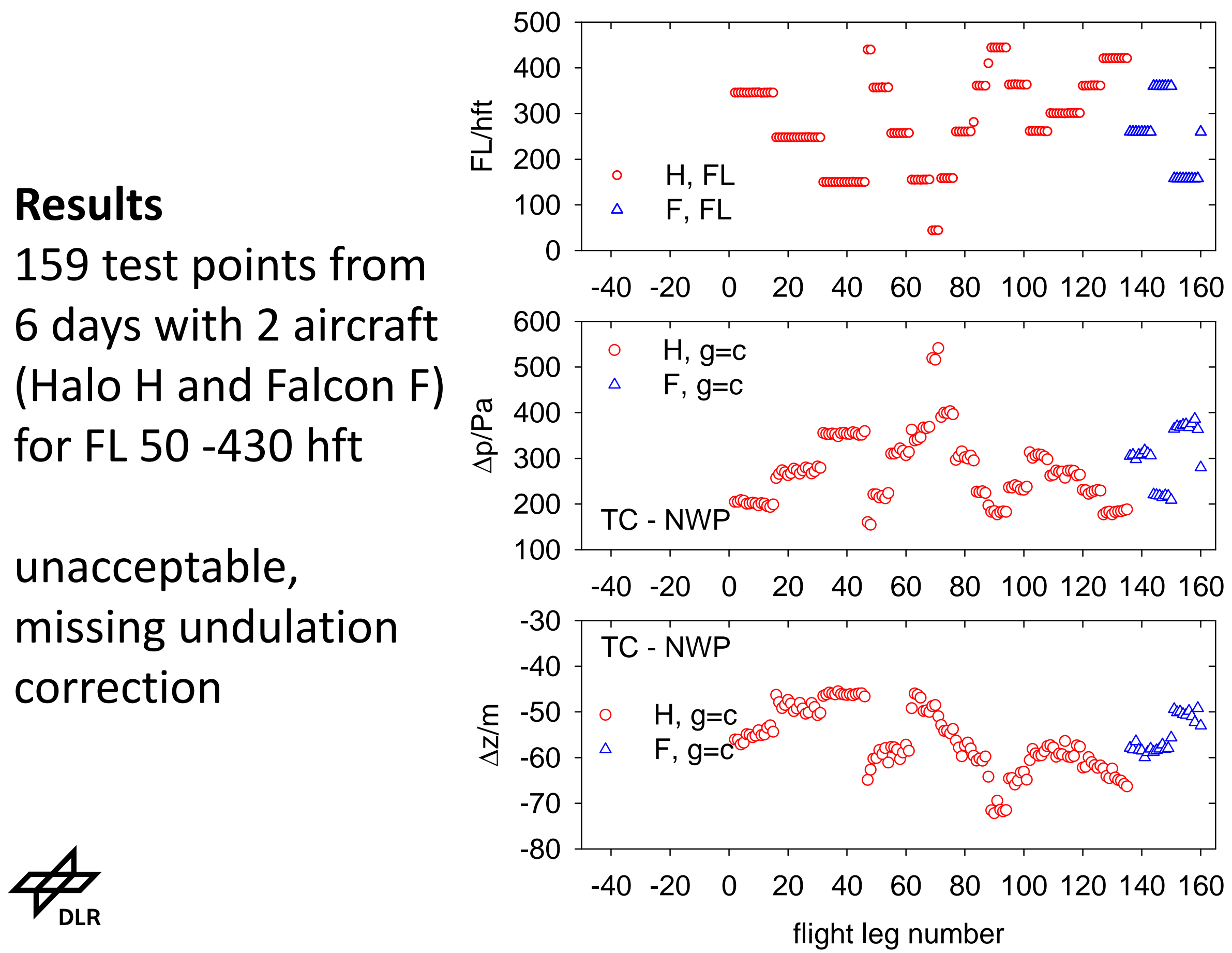


\section{IFS Temperature bias compared to radiosondes vs forecast time: $<0.2 \mathrm{~K}$ below $150 \mathrm{hPa}$}

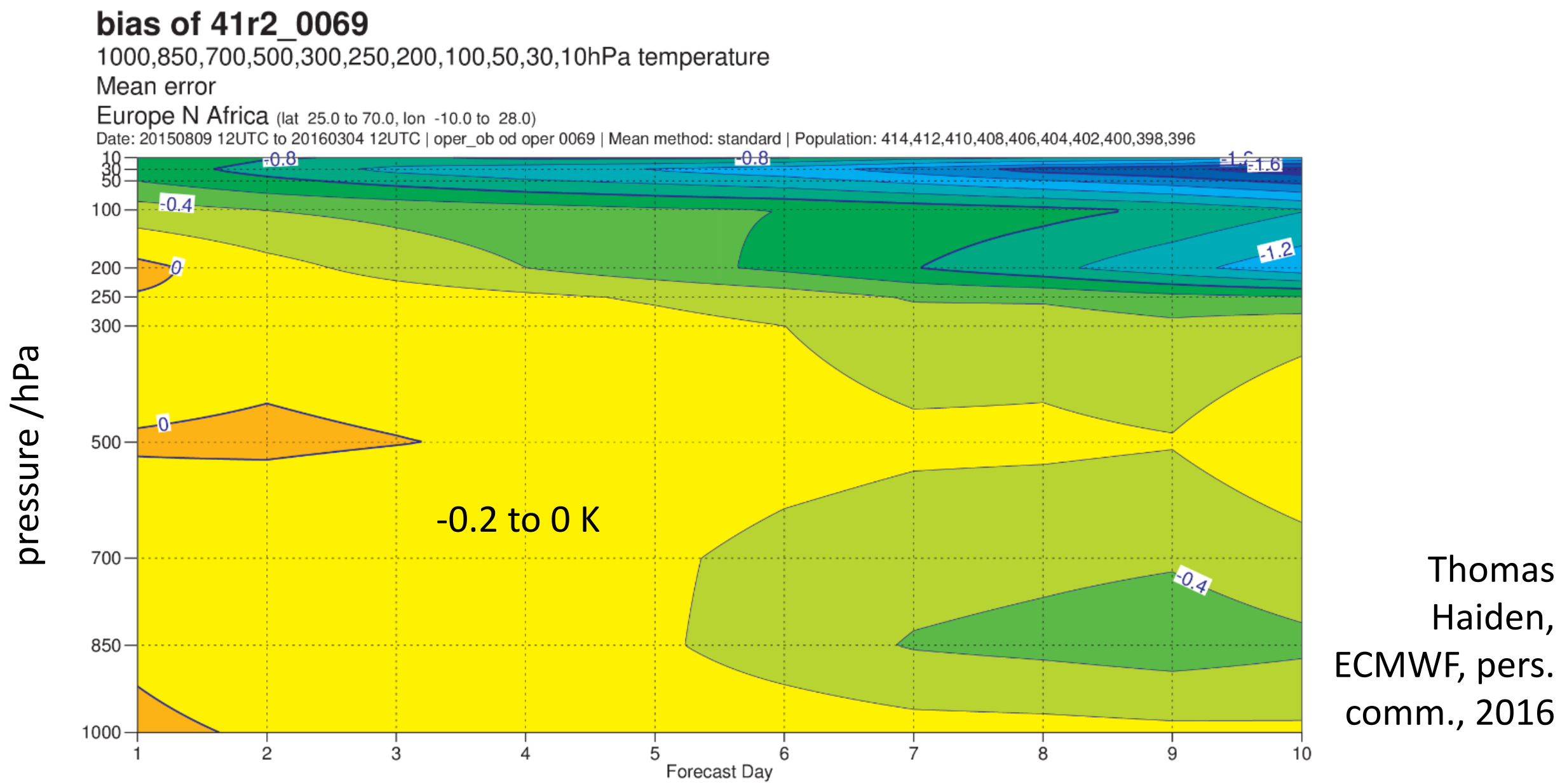

Figure 1. Mean error (top) and RMSE (bottom) of the IFS temperature forecast over Europe, verified against uncorrected radiosonde data, as a function of height and forecast range. Verification period is 9 Aug $2015-4$ March 2016. The model version verified is 41r2, which became operational in March 2016. 


\section{Temperature rms compared to radiosondes vs forecast time}

\section{$<1 \mathrm{~K}$}

41r2 0069

$1000,850,700,500,300,250,200,100,50,30,10 \mathrm{hPa}$ temperature

Root mean square error

Europe N Africa (lat 25.0 to 70.0 , lon -10.0 to 28.0 )

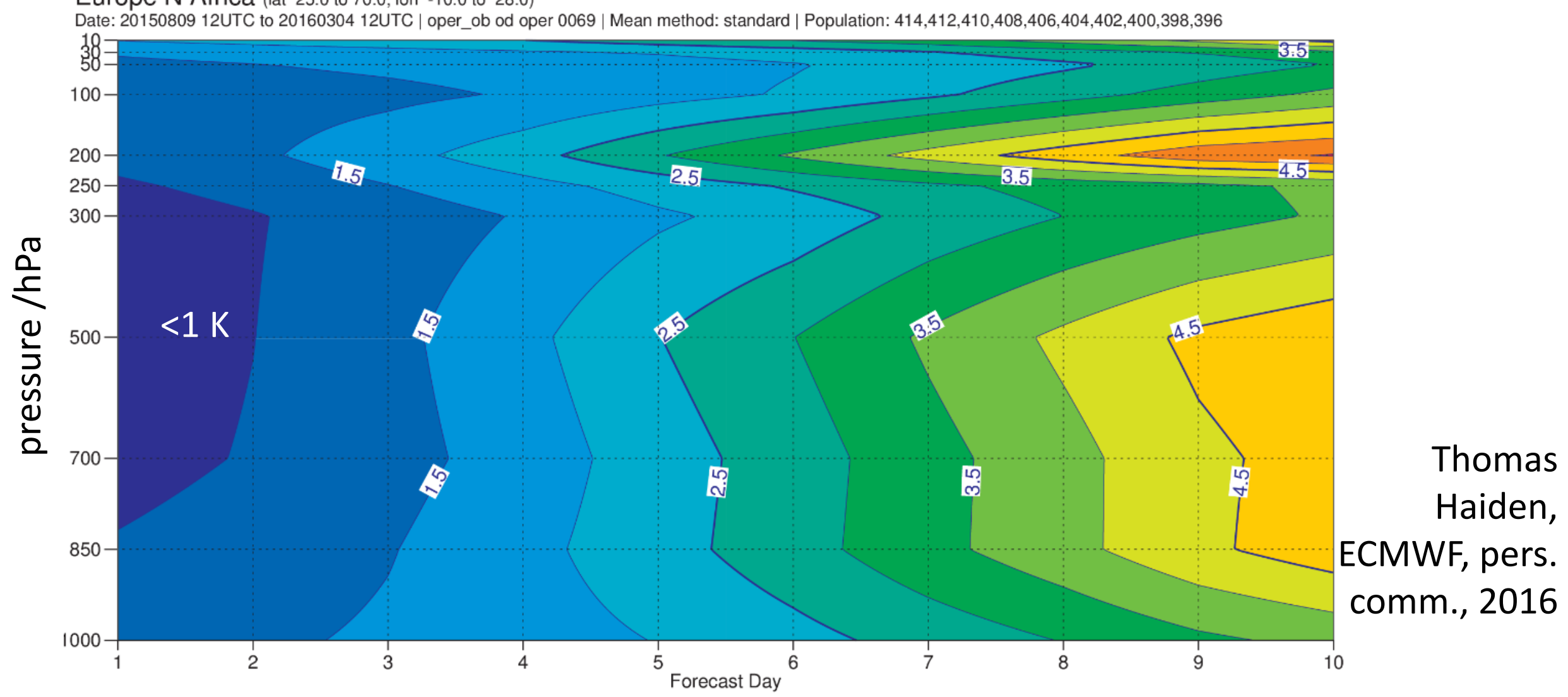

Figure 1. Mean error (top) and RMSE (bottom) of the IFS temperature forecast over Europe, verified against uncorrected radiosonde data, as a function of height and forecast range. Verification period is 9 Aug 2015 - 4 March 2016. The model version verified is 41r2, which became operational in March 2016. 
Low sensitivity to Mach number, time of day, number of flight, and aircraft ( $H$ or F)

Smaller deviations for variable $g$ than for constant g
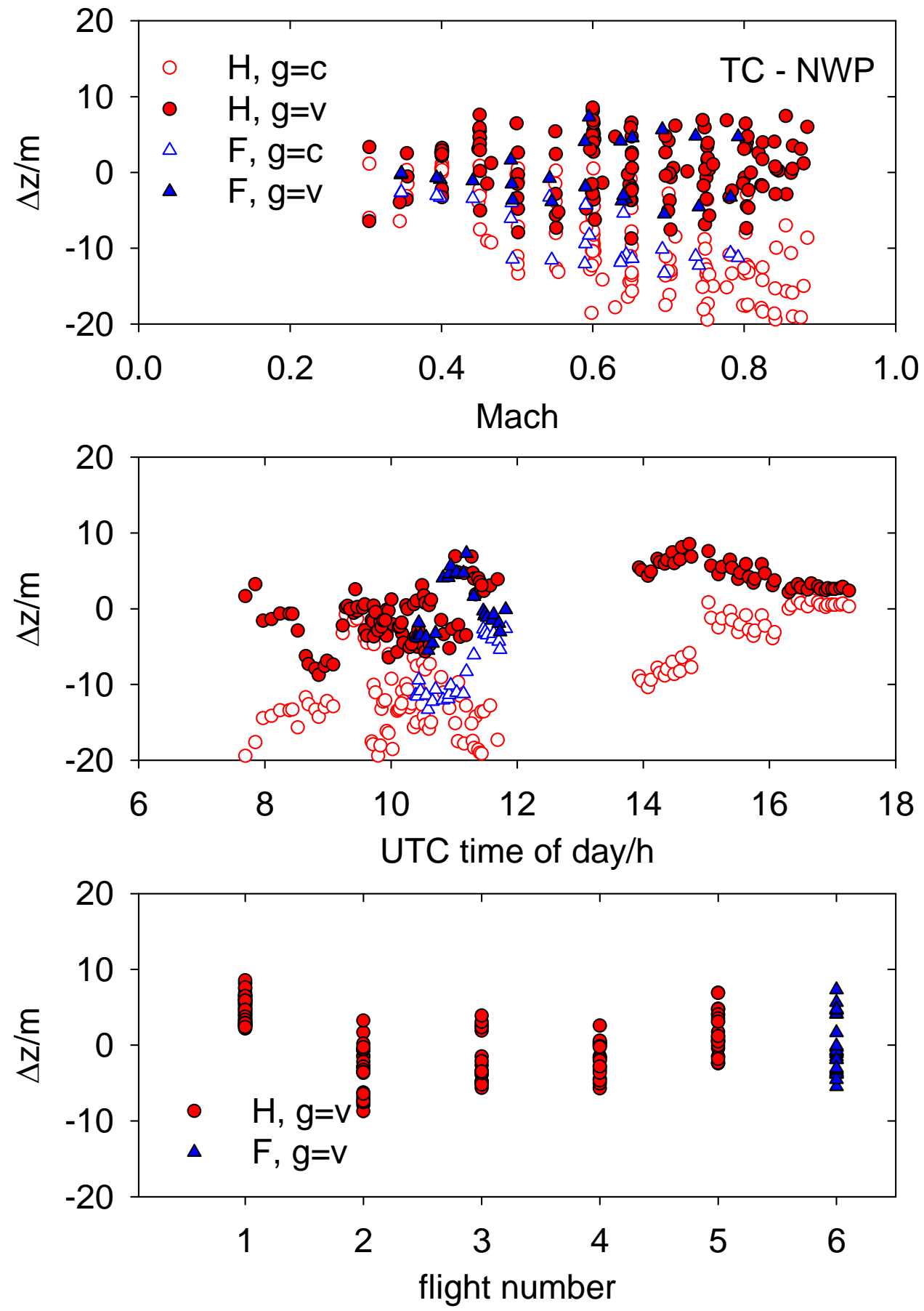
Low random errors

(deviations of single values from average over legs at constant FL)

$$
\begin{gathered}
\Delta z^{\prime}<3 \mathrm{~m}, \\
\Delta \mathrm{p}^{\prime}<20 \mathrm{~Pa}
\end{gathered}
$$

Significantly smaller deviations for variable $g$ than for constant $g$

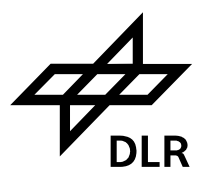

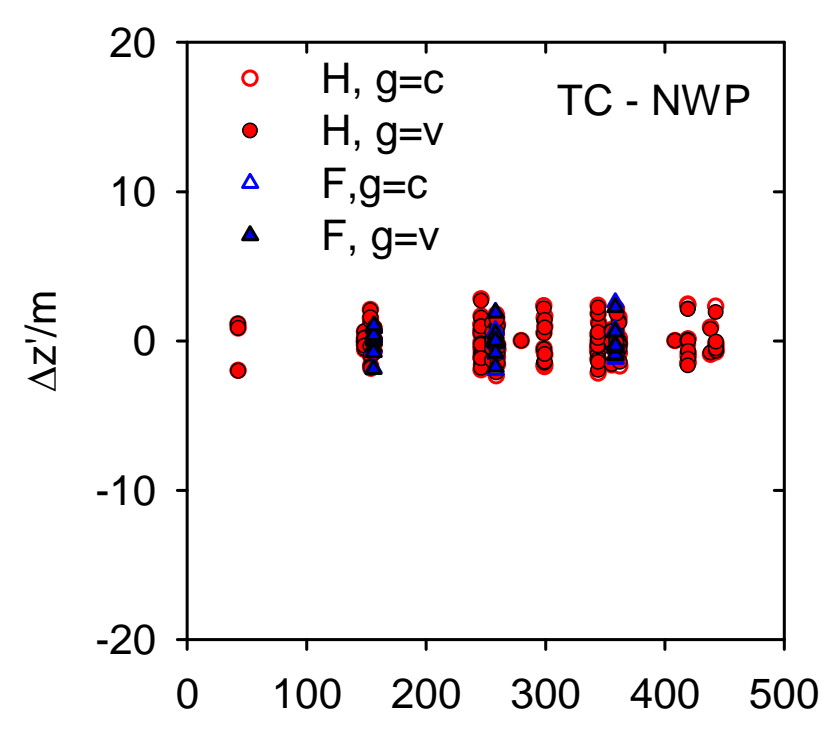
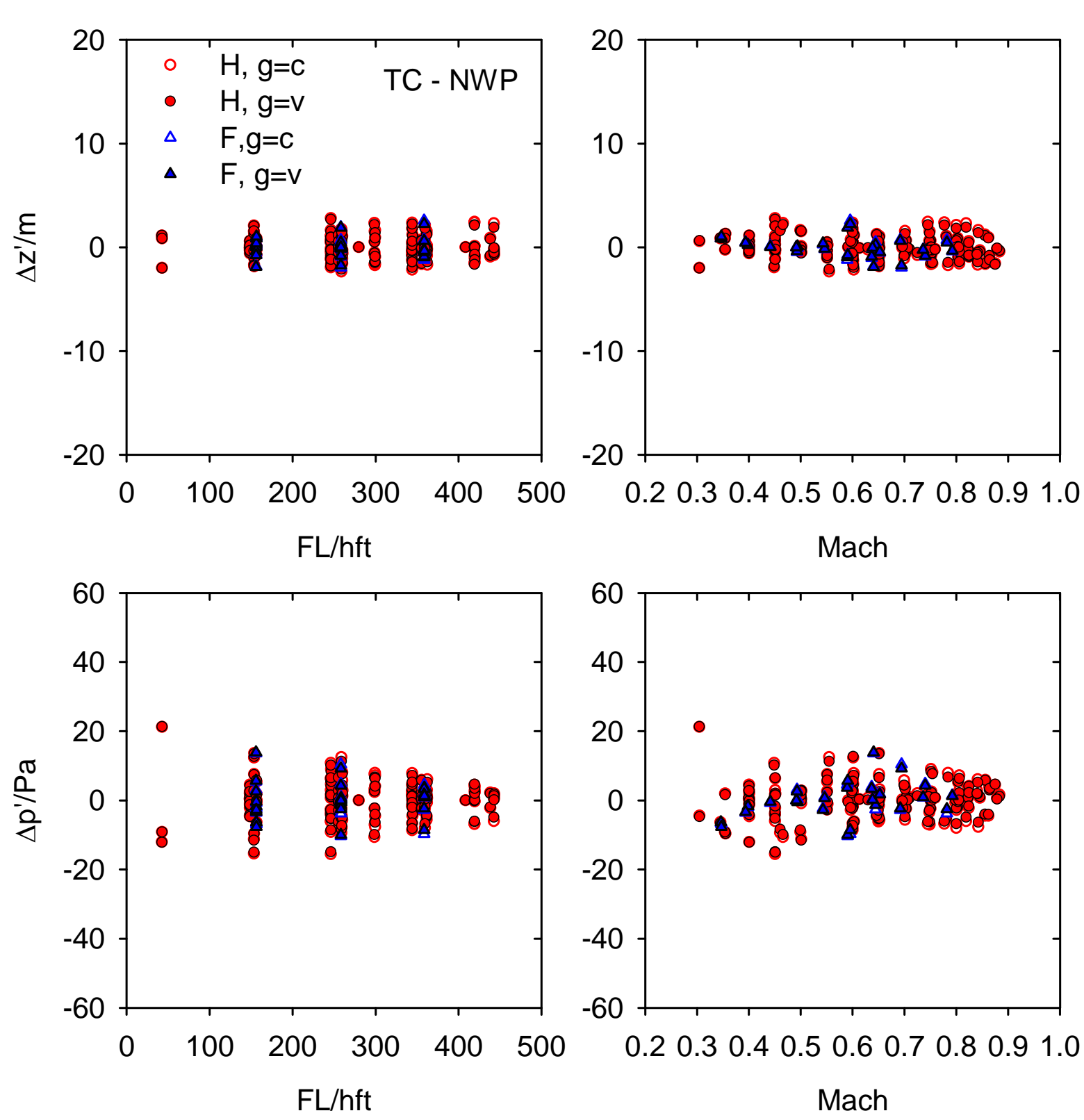